\title{
CAMA
}

Centre for Applied Macroeconomic Analysis

\section{Secular Stagnation and Low Interest Rates under the Fear of a Government Debt Crisis}

\section{CAMA Working Paper 40/2020 April 2020}

\section{Keiichiro Kobayashi}

Keio University

Canon Institute for Global Studies (CIGS)

\section{Kozo Ueda}

Waseda University

Canon Institute for Global Studies (CIGS)

Centre for Applied Macroeconomic Analysis, ANU

\section{Abstract}

In this study, we explain the driving forces behind the secular stagnation associated with a persistent decrease in interest rates. To do so, we employ a model that incorporates a crisis risk triggered by an accumulation of government debt. The model shows that the fear of large-scale taxation on capital and misallocations of capital in future debt crises explains almost half the economic slowdown in Japan over the past two decades. Over the same period, the government bond yield decreases, because the uncertainty in returns on capital makes investing in government bonds becomes less risky than investing in capital. 


\title{
Keywords
}

Default, government bond, capital levy, lost decades, bank run

\author{
JEL Classification
}

E32, E62, G18, H12, H63

\section{Address for correspondence:}

(E) cama.admin@anu.edu.au

ISSN 2206-0332

The Centre for Applied Macroeconomic Analysis in the Crawford School of Public Policy has been established to build strong links between professional macroeconomists. It provides a forum for quality macroeconomic research and discussion of policy issues between academia, government and the private sector.

The Crawford School of Public Policy is the Australian National University's public policy school, serving and influencing Australia, Asia and the Pacific through advanced policy research, graduate and executive education, and policy impact. 


\title{
Secular Stagnation and Low Interest Rates under the Fear of a Government Debt Crisis
}

\author{
Keiichiro Kobayashi* Kozo Ueda ${ }^{\dagger}$
}

April 17, 2020

\begin{abstract}
In this study, we explain the driving forces behind the secular stagnation associated with a persistent decrease in interest rates. To do so, we employ a model that incorporates a crisis risk triggered by an accumulation of government debt. The model shows that the fear of large-scale taxation on capital and misallocations of capital in future debt crises explains almost half the economic slowdown in Japan over the past two decades. Over the same period, the government bond yield decreases, because the uncertainty in returns on capital makes investing in government bonds becomes less risky than investing in capital.
\end{abstract}

JEL Classification Numbers: E32, E62, G18, H12, H63

Keywords: default; government bond; capital levy; lost decades; bank run

\footnotetext{
${ }^{*}$ Keio University and Canon Institute for Global Studies (CIGS) (E-mail: kobayashi@econ.keio.ac.jp).
}

${ }^{\dagger}$ Waseda University, Canon Institute for Global Studies (CIGS), and Centre for Applied Macroeconomic Analysis (CAMA) (E-mail: kozo.ueda@waseda.jp). We would like to thank Kenneth West (Editor), three anonymous referees, Tamon Asonuma, Gauti Eggertsson, Ippei Fujiwara, Masazumi Hattori, Fumio Hayashi, Selo Imrohoroğlu, Takatoshi Ito, Etsuro Shioji, and the conference and seminar participants at the Bank of Japan, CIGS, Columbia University, IMF, Japanese Ministry of Finance, and Summer Workshop on Economic Theory for their useful comments and suggestions. This research was funded by the JSPS Grant-in-Aid for Scientific Research (Japan) (19H01491 for Ueda). All remaining errors are our own. 


\section{Introduction}

The Great Recession of the late 2000s raised concerns over a subsequent secular stagnation (Hansen, 1939) that would cause US and European economies to stagnate persistently in the coming decades (Gordon, 2012; Krugman, 2013; Summers, 2013). Such an effect has been evident in Japan, which has experienced th so-called lost decades since the collapse of the asset market bubble around 1990. Although there are many possible reasons for secular stagnation, ${ }^{1}$ we focus on the fact that this concern arose when government bonds outstanding (GBO) in these countries started to expand substantially. Moreover, it is equally important to emphasize that, despite this development, not only did the interest rate on government bonds not increase, it actually decreased to historically lowest levels.

This study contributes to the literature by offering a new explanation for the factors that drive secular stagnation and a lower government bond yield, based on a simple model. The key factor is a government debt crisis. This results in a complete loss of market confidence in government debt, which forces the government to collect extremely large tax revenues. On the one hand, when a crisis hits an economy, the government is forced to reduce its debt by imposing a once-and-for-all increase in taxes on, for example, GBO (a partial default of government debt), capital stock (capital levy), and consumption. On the other hand, in normal periods, taxes are low, and thus the government budget is not balanced. As a result, government debt continues to rise over time. A crisis occurs with an exogenous probability that increases with the GBO. Using a simple neoclassical closed-economy model, we show that the fear of a government debt crisis causes a persistent economic slowdown in normal times.

The model works as follows. In normal periods, people anticipate that the return on capital will be reduced during a crisis by a heavy tax on capital stock and/or misallocations of capital caused by bank runs triggered by a partial default on GBO. In this case, the fear of a crisis increases the required return on capital and discourages capital investment. This adverse effect is intensified by the accumulation of government debt, because the probability of a government debt crisis increases. Moreover, the tax distortion in a crisis increases with GBO because the government imposes higher tax rates in order to repay its debt. Consequently, a growing risk of a government debt crisis persistently depresses not only the level but also the growth rate of output. The latter result is a novel contribution to the literature, because previous studies have tended to find that a constant risk of disaster reduces the level of output only (e.g., Kozlowski, Veldkamp, and Venkateswaran, 2015).

The model further shows that the fear of a capital levy and a misallocation of capital decreases the government bond yield, which is consistent with the Japanese data. People expect their capital to lose values in a crisis, whereas bond holdings are not taxed heavily. As a result, they consider investing in capital to be riskier than investing in government bonds, and thus choose to buy more bonds and less capital. This increase in demand for bonds reduces the bond yield, despite the accumulation of GBO.

\footnotetext{
${ }^{1}$ Examples include a slowdown in innovations (Gordon, 2012), a demand shortfall (Summers, 2013; Eggertsson, Mehrotra, and Robbins, 2019), and pessimism (Benigno and Fornaro, 2018). Focusing on Japan, Hayashi and Prescott (2002) note the effect of a decrease in the total factor productivity (TFP) growth rate, and Caballero, Hoshi, and Kashyap (2008) emphasize a malfunctioning financial sector.
} 
In our model, the key to the increase in the required return on capital is the tax on capital stock. However, it seems problematic to posit that the fear of a capital levy is widespread when government debt increases, while the fear of government bond defaults is small. To quantify the model, we calibrate key parameter values associated with taxes by reviewing the case of Japan during its economic crisis after World War II. ${ }^{2}$ We show that the post-war Japanese government imposed a heavy wealth tax to avoid default. Furthermore, our model incorporates bank runs that cause severe misallocations of capital stock during a crisis, which reinforces the adverse effect of GBO on capital investment. Our simulation calibrated to Japan demonstrates that the expectation of heavy taxes on capital and misallocations of capital in a crisis accounts for about half of the output slowdown in Japan during the first two decades of the 21st century.

We also examine the case of a preemptive tax hike, where the government introduces a distortionary consumption tax in normal times to prevent a debt crisis from occurring. We find that a preemptive tax hike increases social welfare.

\section{Background}

Economic slowdowns coincide with debt increases in many economies. Figure 1 shows the trend in real GDP per capita and government debt for Japan, the United States, 17 countries in the euro area, and Italy. The graph begins at 1975 for Japan and at 1992 for the other countries, which represents the 15-year periods before the financial crisis in each region (i.e., 1990 and 2007, respectively, shown as vertical dashed lines). The thick solid line represents the logarithm of real GDP per capita, and the thin solid line represents its linear trend (left axis). The line with crosses and the line with circles represent the ratio of gross and net government debt, respectively, to nominal GDP (right axis). The figure shows that government debt increased in all regions after a financial crisis. Notably, Japan's gross government debt now exceeds 200\% of its nominal GDP; net government debt is around $120 \%$ of the nominal GDP. Together with the increase in GBO, real GDP decreased compared with its trend persistently. Hereafter, we provide further empirical evidence related to Japan.

Although this government debt accumulation is commonly cited as the result rather than the cause of the stagnation, Figures 2 and 3 show that increased government debt indeed causes anxiety in Japan. According to a household survey conducted by Japan's Cabinet Office "Overview of the Public Opinion Survey on the Life of the People," an increasing number of Japanese are worried in their everyday lives and about their prospects, with one-third indicating that the fiscal balance is one of the reasons for this. ${ }^{3}$

The left-hand panel of Figure 3 shows the number of occurrences of specific words in the morning and evening editions of the Nihon Keizai Shinbun, Japan's financial newspaper, for the period 1981 to 2019. Words that suggest a government debt crisis, that is, "fiscal failure"

\footnotetext{
${ }^{2}$ Kozlowski, Veldkamp, and Venkateswaran (2015) assume that expectations on tail events are formed by learning from history.

${ }^{3}$ Health and natural disasters are the top two reasons, followed by concerns about public services. This worry is also considered to be related to the accumulation of government debt, which may prevent the government from providing sufficient public services in the future, such as pensions, medical services, and investment in infrastructure resilient to disasters.
} 
(zaisei hatan) or "fiscal crisis" (zaisei kiki), have appeared increasingly frequently since 1981. Moreover, combinations of "tax increase" (zozei) and either "fiscal failure" or "default" are becoming increasingly common too, which seems to suggest a growing fear of a tax increase in the event of a government debt crisis. Although the euro crisis around 2010 caused a sharp increase in these terms, we confirm a steady increase even when we exclude the term "Europe."

The right-hand panel of Figure 3 shows the time-series movements of the sovereign credit default swap (CDS) spread for five-year Japanese government bonds from 2003 to 2019. Sovereign CDS contracts protect investors against sovereign default, which helps us calculate the probability of sovereign default numerically. Similarly to the occurrences of specific words in the left-hand panel, the euro crisis around 2010 contributes to the increase in the CDS spread. However, if we exclude this episode, we find that the CDS spread in the latter half of 2010s is several percentage points higher than that in the mid-2000s.

Furthermore, Morikawa $(2016,2017)$ conduct surveys to examine the subjective probability of a government debt crisis in Japan. He finds that Japanese consumers and firm managers believe that a debt crisis will occur by 2030 with probability around $24 \%$ (consumers) and $27 \%$ (firm managers), on average. However, the survey is such that respondents can interpret it in different ways.

A noteworthy puzzle is that the price (yield) of government bonds is high (low). The lefthand panel of Figure 4 shows the government bond yield in real terms for Japan. This is defined as the nominal bond yield with five-year maturity minus the annual CPI inflation rate in the following year. ${ }^{4}$ The figure shows that bond yields have decreased, which hardly suggests a mounting risk of public default.

At the same time, the return on capital seems to increase. The right-hand panel of Figure 4 shows the increase in the credit spread, which is defined as the bank loan rate with one-year maturity or longer minus the government bond yield with five-year maturity. Data taken from the JIP Database 2015, compiled by the Research Institute of Economy, Trade and Industry in Japan, suggests that the capital cost spread, a proxy for the credit spread, has been increasing. As a result, the ratio of investment to capital has been decreasing.

\section{Literature Review}

Empirical studies report that economies tend to stagnate when government debt is high, ${ }^{5}$ referred to by Reinhart, Reinhart, and Rogoff (2012) as the public debt overhang. They review 26 cases of high government debt in advanced countries, reporting that in 23 cases, economic growth remained stagnant for more than a decade. Based on their finding of a nonlinear correlation between higher debt and lower growth, they argue that an increase in government debt causes lower economic growth. Our study provides a theoretical basis for the public debt overhang.

\footnotetext{
${ }^{4}$ For 2019, we use the realized inflation rate from 2018 to 2019.

${ }^{5}$ See Reinhart and Rogoff (2010), Reinhart, Reinhart, and Rogoff (2012), Checherita-Westphal and Rother (2012), and Baum, Checherita-Westphal, and Rother (2013) for the negative effect of government debt on output. Barro and Sala-i-Martin (1995) show that government consumption has a negative impact on output. Fischer (1991) shows that a fiscal deficit has a negative impact on output.
} 
The literature on sovereign default is unquestionably related to our study. For example, Cole and Kehoe (2000), Aguiar, Amador, and Gopinath (2009), Aguiar and Amador (2011), Bocola (2016), Balke (2017), and Arellano, Bai, and Mihalache (2018) propose models in which a sovereign default risk decreases capital formation and causes a recession before a default occurs. ${ }^{6}$ The most important difference between these studies and ours is that we seek to explain the decrease in the government bond yield, despite the increase in GBO, peculiar to episodes of secular stagnation (e.g., the lost decades of Japan). Thus, the type of government debt crisis we describe in the model does not necessarily refer to a large-scale sovereign default. The government repays most of its debt by imposing large-scale taxes (notably, a capital levy) on private agents, which contributes to a stable government bond price and an increasing credit spread. From a historical perspective, capital levies have been studied by Japan's Ministry of Finance (MOF, 1976) and Eichengreen (1989). Aguiar and Amador (2011) theoretically show that the fear of a capital levy (expropriation) slows economic growth. However, they do not investigate the decrease in the government bond yield.

With regard to the low and stable government bond yield, Hoshi and Ito (2014) point out that Japanese government bonds are held predominantly by Japanese institutional investors, arguing that they have a strong home bias. However, their simulation results show that the amount of government debt will exceed the private sector financial assets within 10 years, and thus they warn of a potential fiscal crisis. Sakuragawa and Sakuragawa (2016) explain the low yield of government bonds by the absence of safe assets. Caballero and Simsek (2017) point out a secular increase in risk intolerance.

Our study is also related to the literature in the 1990s on the non-Keynesian effect of fiscal policy developed by Giavazzi and Pagano (1990), Alesina and Perotti (1996), Alesina and Ardagna (1998), and Perotti (1999). Perotti (1999) shows theoretically and empirically that an increase in government debt has a contractionary effect on consumption when government debt is large. Alesina and Perotti (1996) and Alesina and Ardagna (1998) show that government expenditure cuts have a longer-lasting effect on improving the economy than do tax increases. Our study leads to similar implications, in that an increase in government debt has a contractionary effect. However, our focus is more on long-term growth, in line with the recent work of Reinhart, Reinhart, and Rogoff (2012), rather than short-term effects, which have been studied extensively in the literature on the non-Keynesian effect of fiscal policy.

\footnotetext{
${ }^{6}$ Aguiar, Amador, and Gopinath (2009) and Arellano, Bai, and Mihalache (2018) propose small-open economy models, in which the government and households are the same agent, and sovereign debt is external, whereas it is domestic in our model. This increases the incentive to declare a default. Furthermore, some investors have access to global financial markets, which makes the exogenous world interest rate risk free. In contrast, there is no risk-free asset in our model. This helps stabilize the price of government bonds, despite an increase in GBO. Moreover, in the aforementioned models, the government's default decision is endogenous, whereas a crisis occurs with an exogenous probability in our model. The model of Bocola (2016) is similar to ours. In his model, the government's default decision is exogenous. Furthermore, banks hold government bonds, and the fear of sovereign default tightens banks' funding constraints. However, our model accounts for the slowdown of long-term growth, whereas that of Bocola (2016) explains a short-term decline in output. In addition, our model accounts for the negative correlation between the government bond yield and the amount of government debt. Cole and Kehoe (2000) consider an optimal government policy in which government debt is rolled over every period. In this case, there is a risk of a self-fulfilling default caused by a loss of confidence in the government.
} 
Theoretically, the model presented in this paper is a neoclassical model of rare disaster, following the work of Rietz (1988), Barro (2006, 2009), Gabaix (2012), and Gourio (2012, 2013). Specifically, our model is a simplified version of that of Gourio (2013). However, the properties of the "disaster" in our case are different, because a debt crisis is an abrupt redistribution of wealth, whereas a disaster destroys resources. Therefore, we refer to a crisis rather than disaster. In our model, a crisis affects mainly the household (through taxes), whereas a disaster in Gourio (2013) affects firms through changes in their productivity and capital values. ${ }^{7}$

The remainder of this paper proceeds as follows. Section 2 introduces the basic model and specifies the equilibrium. Section 3 presents the analytical results on the two-period version of the model. Section 4 presents the results of the numerical simulation. Section 5 presents several extensions of our analyses, and Section 6 concludes.

\section{Model}

The model economy consists of a representative household, firm, bank, and government. For simplicity, we assume that, in normal times, the government makes a transfer, but collects no tax. ${ }^{8}$ Thus, government debt keeps increasing. When a crisis occurs, the government imposes once-and-for-all taxes on the household in order to repay its debt. The crisis probability is given exogenously, and increases with the GBO. We assume a closed economy, because around $90 \%$ of government bonds are held by domestic investors in Japan. ${ }^{9}$ The asset market is incomplete, meaning that the crisis risk is not insured.

\section{Crisis Risk}

Define a crisis indicator $x_{t}$ as $x_{t}=0$ in normal times, and as $x_{t}=1$ when a government debt crisis occurs. The variable $x_{t}$ is an exogenous sunspot shock to the economy. A government

\footnotetext{
${ }^{7}$ Kozlowski, Veldkamp, and Venkateswaran (2015) use Gourio's model to analyze the exogenous disaster risk of a financial crisis. Isore and Szczerbowicz (2017) later extend this work to the New Keynesian model. Kunieda (2015) applies Barro's (2006) model to the risk of a natural disaster.

${ }^{8}$ This assumption is for simplicity. In reality, there are at least four issues related to government policy in normal times: (i) the government may increase tax to reduce its debt. Bohn (1998) and Lo and Rogoff (2015) report empirically that governments tend to improve their fiscal balance in response to an increase in their debt (see also Aguiar et al., 2015; Bianchi, Hatchondo, and Martinez, 2018); (ii) the government may impose a number of distortionary taxes; (iii) government spending is counter-cyclical and tax revenue is pro-cyclical; and (iv) $G_{t}$ may not necessarily be a transfer, but government spending on goods. However, these tax and spending policies in normal times do not affect our main results qualitatively, because we focus on how changes in tax policy from normal times to a crisis event influence economic activity. Moreover, with regard to issue (i), the political costs are considered to be large, given that very few countries implement policies that are sufficiently conservative to eliminate the possibility of a crisis. Issue (iii) strengthens our results quantitatively, because the risk of a government debt crisis causes a larger decrease in output and investment when GBO increases more rapidly. Issue (iv) may have implications for the optimality of tax smoothing. However, this does not matter for our main results because our main analysis is not normative.

${ }^{9}$ Reinhart and Rogoff (2010) emphasize the importance of domestic debt.
} 
debt crisis occurs when holders lose confidence in the government debt and rush to exchange it for real assets and goods, which is exogenous to the government actions.

A crisis has two main consequences. First, the government is forced to raise a substantial amount in tax revenue. ${ }^{10}$ The government imposes a once-and-for-all tax only at the time of the crisis, where $\tau_{t}^{C}$ is the consumption tax rate, $\tau_{t}^{K}$ is the tax rate on capital stock, and $\tau_{t}^{G}$ is the tax rate on GBO. Note that the latter two taxes are wealth taxes, not taxes on the net returns from holding these assets. The tax on GBO is essentially equivalent to a partial default (a full default when $\tau^{G}=1$ ). ${ }^{11}$ The tax on capital stock, also called a capital levy, turns out to play the most important role in explaining persistent recessions.

Second, when a crisis occurs, banks become insolvent. Because banks and other financial institutions hold government debt as a large part of their assets, it is straightforward that a decrease in the value of government debt will make them insolvent. Then, all depositors rush to withdraw early, and banks are forced to sell productive capital as well as government bonds to finance the early withdrawals (bank runs), causing fire sales of productive capital. These fire sales misallocate capital stock within the economy, making it used inefficiently and decreasing its aggregate value. From the household's perspective, this reduction in capital value works as a capital levy.

On the other hand, in normal times, a randomly selected fraction $\theta(0<\theta<1)$ of depositors withdraw early, and the bank can finance the early withdrawals by selling government bonds only. Thus, we assume that bank runs do not occur in normal times.

The probability that a crisis occurs in period $t+1$ is denoted by $p_{t}=p\left(B_{t}^{G} / z_{t}\right)=\operatorname{Pr}\left(x_{t+1}=\right.$ $1 \mid B_{t}^{G} / z_{t}$ ), where $B_{t}^{G}$ is the quantity of government bonds and $z_{t}$ is productivity (TFP), given by $\log z_{t+1}=\log z_{t}+\mu+\sigma_{e} e_{t+1}$, where $e_{t+1} \sim N(0,1)$. This probability depends positively on the GBO divided by the TFP. We assume the following logistic form:

$$
p_{t}=p\left(B_{t}^{G} / z_{t}\right)=\frac{1}{1+\left(1 / d_{0}-1\right) \exp \left(-d_{1} B_{t}^{G} / z_{t}\right)},
$$

where $d_{0}$ represents the crisis probability in the next period when there is no government debt today, and $d_{1}$ represents the steepness of the crisis probability curve with respect to the GBO divided by the TFP. ${ }^{12}$

The crisis probability (1) can be interpreted as a reduced form, because it can be derived as an equilibrium outcome of a model in which the government decides endogenously whether or not to default on the debt. ${ }^{13}$ Though the sovereign debt in the models documented in

\footnotetext{
${ }^{10}$ The government debt crisis in our model is essentially a rollover crisis, in that the government does not need to repay all of its debt. However, even part of its debt is likely to be sizable, because it accounts for around a quarter of government expenditure in Japan. At the same time, the government relies on the issuance of new government bonds by as much as $30 \%$. Thus, when a crisis causes a complete loss of market confidence in government debt, it is plausible that the government will be forced to collect extremely large tax revenues. Indeed, this was the case in post-war Japan.

${ }^{11}$ Although our model is a real model without an explicit role for the nominal variables, a partial default in our model can be interpreted as a debt reduction by inflation tax or seigniorage.

${ }^{12}$ Specifically, we assume that $p_{t}$ becomes one (a crisis occurs for sure) if the tax rate on either capital or GBO during the crisis becomes one or greater.

${ }^{13} \mathrm{~A}$ crisis is more likely to occur as the GBO increases (Reinhart and Rogoff, 2010). Arellano (2008) constructs
} 
footnote 13 is external debt, similar reasoning would hold for the domestic debt in our model. ${ }^{14}$ Abstracting away from modeling the government's default decision, we discuss the equilibrium dynamics of macroeconomic variables by focusing on optimizations by private agents.

\section{Household}

There exists a unit mass of identical households. A household has the nonseparable lifetime utility $U_{t}$, defined as

$$
U_{t}^{1-\psi}=(1-\beta)\left(C_{t}^{\nu}\left(1-N_{t}\right)^{1-\nu}\right)^{1-\psi}+\beta E_{t}\left(U_{t+1}^{1-\psi}\right),
$$

where $\beta$ represents a discount factor, $\psi$ represents the intertemporal elasticity of the substitution of consumption, and $\nu$ represents a utility weight on consumption. The utility function takes the standard Cobb-Douglas form in consumption $C_{t}$ and leisure $1-N_{t}$, where $N_{t}$ is the labor supply, which is consistent with balanced growth.

Owing to the inefficiency described below, the household holds the certificate of bank deposit $D_{t}$ rather than holding capital stock $K_{t}$ and government bonds $B_{t}^{G}$ directly. ${ }^{15}$ The rate of return on the bank deposit is denoted by $R_{t}^{D}\left(x_{t}\right)$. Then, the budget constraint for the household is written as

$$
\left(1+x_{t} \tau_{t}^{C}\right) C_{t}+x_{t} T_{t}+D_{t+1} \leq R_{t}^{D}\left(x_{t}\right) D_{t}+G_{t}+W_{t} N_{t}
$$

where $T_{t}$ is the lump-sum tax, $G_{t}$ is the lump-sum transfer from the government, and $W_{t}$ represents the real wage. This implies that

$$
E_{t}\left[M_{t+1} R_{t+1}^{D}\left(x_{t+1}\right)\right]=1
$$

where $M_{t+1}$ is the stochastic discount factor:

$$
M_{t+1}=\beta\left(\frac{1+x_{t} \tau_{t}^{C}}{1+x_{t+1} \tau_{t+1}^{C}}\right)\left(\frac{C_{t+1}}{C_{t}}\right)^{\nu(1-\psi)-1}\left(\frac{1-N_{t+1}}{1-N_{t}}\right)^{(1-\nu)(1-\psi)} .
$$

a small open-economy model, showing that a default is more likely to occur in a recession, which is consistent with the data. She points out that this result is due to the incomplete asset market, whereas models based on a complete asset market tend to predict the opposite result. D'Erasmo and Mendoza (2016) show theoretically that a default on domestic government debt is more likely when the debt is larger and the tax revenue is smaller. Arellano, Bai, and Mihalache (2018), with some additional uncertainty in the preference of the government, imply that the crisis probability increases with the GBO. In contrast, the probability of a default is arbitrary in the self-fulfilling crisis model of Cole and Kehoe (2000); however, this does not deny the assumption that a self-fulfilling crisis is more likely to occur as the GBO increases.

${ }^{14}$ We can consider the following decision problem for the government on whether to default on its debt. Here, the default occurs exogenously with a constant probability, even if the government chooses not to default. Given that the distortion of a default grows as the debt increases, the government faces tension between defaulting today or in the future. Then, the government optimally defaults if its debt exceeds an endogenous threshold. Adding a preference shock on the government due to the stochastic event of losing office (Aguiar, Amador, and Gopinath, 2009) would lead to an endogenous default probability, which is increasing in the GBO.

${ }^{15}$ The household can hold government bonds $B_{t}^{G}$, but chooses not to do so, because the rate of return is higher for the bank deposit; that is, $E_{t}\left[M_{t+1} R_{t}^{D}\right] \geq E_{t}\left[M_{t+1}\left(1-x_{t+1} \tau_{t+1}^{G}\right) / q_{t}^{G}\right]$, in equilibrium. The definition of the variables is explained below. 
In order to explain bank runs, we assume that households are ex post heterogenous. A fraction $\theta$ of the households are early withdrawers of the bank deposit. The early payment is made just after the value of crisis indicator $x_{t}$ is revealed, and before output is produced. When $x_{t}$ is zero, late withdrawers withdraw the deposit after output is produced.

\section{Firm}

There is a unit mass of identical firms that face perfect competition. Its production function is expressed as $Y_{t}=K_{t}^{\alpha}\left(z_{t} N_{t}\right)^{1-\alpha}$, where $Y_{t}$ represents output. The static profit maximization is

$$
\pi\left(K_{t}, z_{t} ; W_{t}\right)=\max _{K_{t}, N_{t} \geq 0}\left\{K_{t}^{\alpha}\left(z_{t} N_{t}\right)^{1-\alpha}+(1-\delta) K_{t}-R_{t}^{K} K_{t}-W_{t} N_{t}\right\},
$$

which yields the return on capital $R_{t}^{K}=1-\delta+\alpha Y_{t} / K_{t}$ and $N_{t}=K_{t}\left(z_{t}^{1-\alpha}(1-\alpha) / W_{t}\right)^{\frac{1}{\alpha}}$, where $\delta$ represents the capital depreciation rate.

The household cannot operate $K_{t}$ efficiently for two reasons. First, the household can use only $\lambda_{t}^{Y} K_{t}$ for production, where $\lambda_{t}^{Y}<1$. Second, $\left(1-\lambda_{t}^{D}\right) K_{t}$ is destroyed if the household directly holds and uses $K_{t}$, where $\lambda_{t}^{D}<1$. In a crisis, the household uses $K_{t}$ inefficiently because banks become insolvent, whereas the banks operate capital $K_{t}$ efficiently in normal times. Consequently, the return on capital $R_{t}^{K}\left(x_{t}\right)$ becomes a random variable that depends on $x_{t}$ :

$$
\begin{aligned}
& R_{t}^{K}(1)=\alpha \frac{Y_{t}(1)}{K_{t}}+(1-\delta) \lambda_{t}^{D}, \\
& R_{t}^{K}(0)=\alpha \frac{Y_{t}(0)}{K_{t}}+(1-\delta), \\
& Y_{t}(1)=\left(\lambda_{t}^{Y} K_{t}\right)^{\alpha}\left(z_{t} N_{t}\right)^{1-\alpha}, \\
& Y_{t}(0)=\left(K_{t}\right)^{\alpha}\left(z_{t} N_{t}\right)^{1-\alpha} .
\end{aligned}
$$

\section{Bank}

There is a unit mass of one-period-lived banks. A bank is born, collects deposit, and invest it in capital stock and government bonds at the end of period $t$ to maximize the return on the deposit. It, then, pays out all the return to depositors and ceases to operate in period $t+1$. The deposit contract can be contingent on $z_{t+1}$, but not on $x_{t+1}$. The banks can offer only $R_{t+1}^{D}(0)$, which is the return on a deposit when $x_{t+1}=0$ :

$$
R_{t+1}^{D}(0)=\frac{R_{t+1}^{K}(0) K_{t+1}+B_{t+1}^{G}}{K_{t+1}+q_{t}^{G} B_{t+1}^{G}}
$$

where $q_{t}^{G}$ is the price of government bonds. When $x_{t+1}=1$, the banks adopt the first-comefirst-served principle for depositors. Thus, depositors can withdraw the full amount of their deposits $R_{t+1}^{D}(0) D_{t+1}$ at any time in period $t+1$, as long as the bank asset remains. However, they receive nothing if all bank assets are paid out to early withdrawers. Thus, the average return on a deposit when $x_{t+1}=1$ equals

$$
R_{t+1}^{D}(1)=\frac{\left(1-\tau_{t+1}^{K}\right) R_{t+1}^{K}(1) K_{t+1}+\left(1-\tau_{t+1}^{G}\right) B_{t+1}^{G}}{K_{t+1}+q_{t}^{G} B_{t+1}^{G}} .
$$


Given deposit $D_{t+1}$, the bank's problem is written as

$E_{t}\left[M_{t+1} R_{t+1}^{D}\left(x_{t+1}\right)\right] D_{t+1}=\max _{K_{t+1}} E_{t}\left[M_{t+1}\left\{\left(1-x_{t+1} \tau_{t+1}^{K}\right) R_{t+1}^{K}\left(x_{t+1}\right) K_{t+1}+\left(1-x_{t+1} \tau_{t+1}^{G}\right) B_{t+1}^{G}\right\}\right]$,

subject to the balance sheet constraint $D_{t+1}=q_{t}^{G} B_{t+1}^{G}+K_{t+1}$, and liquidity constraint $B_{t+1}^{G} \geq$ $\Theta_{t+1} D_{t+1}$, where $q_{t}^{G}$ is the price of the government bonds. The latter constraint is necessary because early withdrawers must be served before any output is produced, and the bank can pay out the deposits only by selling government bonds $B_{t+1}^{G}$. In equilibrium, $\Theta_{t+1}$ is determined by $\Theta_{t+1}=\theta\left(R_{t+1}^{K}(0) K_{t+1}+B_{t+1}^{G}\right) / D_{t+1}$. We assume that $B_{t+1}^{G}$ is sufficiently large, such that the liquidity constraint is not binding in equilibrium. Then, the first-order condition with respect to $K_{t+1}$ implies that

$$
E_{t}\left[M_{t+1}\left(1-x_{t+1} \tau_{t+1}^{K}\right) R_{t+1}^{K}\left(x_{t+1}\right)\right]=\frac{1}{q_{t}^{G}} E_{t}\left[M_{t+1}\left(1-x_{t+1} \tau_{t+1}^{G}\right)\right] .
$$

Furthermore, we assume that inefficiency $\lambda_{t}^{Y}$ at the crisis is determined endogenously by

$$
\lambda_{t}^{Y}=F\left(\xi_{t}\right)
$$

where $F^{\prime}(\xi)<0$ and $\xi_{t}$ represents the ratio of nonperforming loans to assets:

$$
\xi_{t} \equiv 1-\frac{\left(1-\tau_{t}^{K}\right) R_{t}^{K}(1) K_{t}+\left(1-\tau_{t}^{G}\right) B_{t}^{G}}{R_{t}^{K}(0) K_{t}+B_{t}^{G}} .
$$

This assumption is based on the premise that production activity by the household necessitates bank deposits as a means of payment, while the function of the means of payment is disrupted if the ratio of non-performing loans is large. In the next section, we provide empirical evidence and calibrate parameter values for this specification.

We define $R_{t}^{G} \equiv 1 / q_{t}^{G}$, and call $R_{t}^{G}-1$ the government bond yield. The price of government bonds, $q_{t}^{G}$, is normally less than one because $M_{t+1}$ is less than one. Therefore, equation (14) suggests that the government bond yield is positive and increases with $\tau^{G}$. However, as discussed below, the government bond yield decreases when the distortion associated with the capital stock increases. In other words, the household prefers to hold the government bond rather than capital. This makes the government bond yield decrease, owing to the no-arbitrage condition between capital and government bonds.

\section{Government}

The government spends by way of a lump-sum transfer $G_{t}>0$, the ratio of which to TFP, $z_{t}$, is constant for all $x_{t}$. Tax is zero if $x_{t}=0$, and nonnegative if $x_{t}=1$. The government budget constraint is given by

$$
q_{t}^{G} B_{t+1}^{G}+x_{t} \tau_{t}^{C} C_{t}+x_{t} \tau_{t}^{K} R_{t}^{K} K_{t}+x_{t} \tau_{t}^{G} B_{t}^{G}+x_{t} T_{t}=B_{t}^{G}+G_{t} .
$$


To determine the tax rates, we assume tax weight $\omega^{i}(i=C, K, G, T)$, which is exogenous and satisfies

$$
\begin{aligned}
\tau_{t}^{C} C_{t} & =\omega^{C}\left(B_{t}^{G}+G_{t}\right), \\
\tau_{t}^{K} R_{t}^{K} K_{t} & =\omega^{K}\left(B_{t}^{G}+G_{t}\right), \\
\tau_{t}^{G} B_{t}^{G} & =\omega^{G}\left(B_{t}^{G}+G_{t}\right), \\
T_{t} & =\omega^{T}\left(B_{t}^{G}+G_{t}\right), \\
0 & <\omega^{C}+\omega^{K}+\omega^{G}+\omega^{T} \leq 1 .
\end{aligned}
$$

If $\omega^{C}+\omega^{K}+\omega^{G}+\omega^{T}=1$, the government issues no new bonds; in other words, it owes nothing after the crisis period.

Although the tax rate is assumed to be zero in non-crisis periods $\left(x_{t}=0\right)$, this assumption is not critical to our results, as long as the government collects insufficient tax to cover its expenditure.

\section{Market Clearing}

The goods market is cleared when

$$
Y_{t}=C_{t}+I_{t}
$$

where investment $I_{t}$ equals $K_{t+1}-(1-\delta) K_{t}$.

The labor market is cleared when

$$
(1-\alpha) \frac{Y_{t}}{N_{t}}=W_{t}=\frac{1-\nu}{\nu} \frac{\left(1+\tau_{t}^{C}\right) C_{t}}{1-N_{t}} .
$$

\section{Equilibrium}

In the economy, the state variables are $\left\{K_{t}, B_{t}^{G}, x_{t}, z_{t}\right\}$; however, as in Gourio (2013), the equilibrium can be expressed using $\left\{k_{t} \equiv K_{t} / z_{t}, b_{t}^{G} \equiv B_{t}^{G} / z_{t}, x_{t}\right\}$. See Appendix A for the calculation of the equilibrium.

In the model, the fear of a government debt crisis can cause persistent stagnation beforehand when people share the expectation that a considerable distortion occurs at the time of a crisis. In particular, two distortions are important. The first is a capital levy, a one-time tax on all wealth holders with the goal of retiring government debt, denoted by $\omega^{K}$ or $\tau_{t}^{K}$. The second is capital-use inefficiency, resulting from bank runs, denoted by $\lambda_{t}^{Y}$ and $\lambda_{t}^{D}$. Both distortions increase the required return to capital, $R_{t+1}^{K}(0)$, in a normal state and, in turn, dampen capital investment before a crisis occurs.

\section{Analysis on a Simplified Two-Period Model}

Before describing our simulation, we provide an overview of the model by presenting the analytical results of a simplified version. The simplified model is a two-period version of the model, in which the banking sector is abstracted away and the household directly holds government 
bonds and capital stock. Time runs from period 0 to 1 . In period 0 , the crisis does not occur. In period 1 , the crisis occurs if $x=1$, and does not occur if $x=0$.

The government budget constraint in period 1 is

$$
B+G=x \tau^{C} C_{1}+x \tau^{K} R_{1}^{K} K+x \tau^{G} B+x T+(1-x) \tilde{T},
$$

where we assume that the debt $B$ is repaid only by the lump-sum tax $\tilde{T}$ if the crisis does not occur $(x=0)$.

In period 0 , the representative household is given the initial asset holdings, $K_{0}$ and $B_{0}$. The household solves the following problem in period 0 :

$$
U_{0}^{1-\psi}=\max _{C_{0}, N_{0}, K, B}(1-\beta)\left\{C_{0}^{\nu}\left(1-N_{0}\right)^{1-\nu}\right\}^{1-\psi}+\beta E_{0}\left(U_{1}(x, K, B)^{1-\psi}\right),
$$

subject to the budget constraint:

$$
C_{0}+q B+K \leq R_{0}^{K} K_{0}+B_{0}+W_{0} N_{0}+G
$$

and $U_{1}(x, K, B)$ is the solution to the period 1 problem:

$$
U_{1}(x, K, B)=\max _{C_{1}, N_{1}} C_{1}^{\nu}\left(1-N_{1}\right)^{1-\nu}
$$

subject to

$$
\left(1+x \tau^{C}\right) C_{1} \leq\left(1-x \tau^{K}\right) R_{1}^{K}(x) K+\left(1-x \tau^{G}\right) B+W(x) N_{1}-x T-(1-x) \tilde{T} .
$$

The firm is modeled as before, producing goods using capital and employment; however, we assume full depreciation in this case $(\delta=1)$. The goods market is cleared as in equation (23).

Then, the following proposition shows that both a slowdown of real economic activity and a decrease in the government bond yield occur in normal times.

Proposition 1 Assume $\tau^{C}=\tau^{G}=0$ and $\tau^{K}>0$. Then, an increase in the initial debt $B_{0}$ makes (i) output $(Y)$ and investment $(K)$ slow down, and (ii) the rate of return on government bonds $(1 / q)$ decreases.

The proof is provided in Appendix B. The results follow because the increasing possibility of a capital levy makes investing in capital is riskier than investing in government bonds. Our analysis in this section has focused on the case where $\tau^{C}=\tau^{G}=0$ and $\tau^{K}>0$. This assumption is reasonable, because the revenue from the consumption tax and the partial default of the government debt is negligibly small during a crisis based on our calibration to the Japanese data (see the next section for details).

\section{Simulation}

Here, we return to the model discussed in Section 2. 


\subsection{Simulation Method}

A time unit is a year. In the model, although the state variables are $\left\{K_{t}, B_{t}^{G}, x_{t}, z_{t}\right\}$, the equilibrium can be expressed using $\left\{k_{t}=K_{t} / z_{t}, b_{t}^{G}=B_{t}^{G} / z_{t}, x_{t}\right\}$. In what follows, we denote the variables divided by $z_{t}$ using lower-case letters (e.g., $y_{t}=Y_{t} / z_{t}$ ), with the exception of $u_{t}$, which is defined as $U_{t}^{1-\psi} / z_{t}^{\nu(1-\psi)}$. Note that the GBO, $b_{t}^{G}$, does not explode, although there is no deterministic steady state. Equation (1) indicates that the crisis probability increases with $b_{t}^{G}$, provided $d_{1}>0$, which stabilizes $b_{t}^{G} \cdot{ }^{16}$

Following Gourio (2013), we solve the model employing a projection method. The policy functions are approximated using two-dimensional Chebychev polynomials with respect to $k_{t}$ and $b_{t}^{G}$, with degree five in each dimension.

\subsection{Calibration}

Table 1 shows the benchmark parameter values we use for the simulation. Many parameter values are standard and based on Gourio (2013); others are chosen to fit Japan, and are based on the work of Sugo and Ueda (2008) and Hirose and Kurozumi (2012). The trend growth rate of TFP, $\mu$, is 0.0182 , which equals the actual annual growth rate of real GDP per capita from 1990 to 2019 for Japan (see Figure 1). ${ }^{17}$ The standard deviation of the productivity shock $\sigma_{e}$ is 0.023 , calibrated to match the standard deviation of the change in output $\left(\Delta \log Y_{t}\right)$ for Japan. Government spending $g=G_{t} / z_{t}$ is chosen as 0.014 to be consistent with the speed of Japan's government debt accumulation.

There are three main parameter categories, each of which needs careful calibration: the tax policy during the crisis $\left(\omega^{i}(i=C, K, G, T)\right)$, capital-use inefficiency during the crisis $\left(\lambda^{Y}\right.$ and $\left.\lambda^{D}\right)$, and probability of the crisis $\left(d_{0}\right.$ and $\left.d_{1}\right)$. We explain our calibration strategy below.

\subsubsection{Tax in a Crisis}

As in Kozlowski, Veldkamp, and Venkateswaran (2015), we assume that expectations on the tax policy at a crisis, $\omega^{i}(i=C, K, G, T)$, are formed by learning from history. A crisis is a typical tail event, about which agents in the economy have no knowledge, other than historical episodes of similar events. Here, capital levy $\omega^{K}$ is particularly important, and so we review episodes in interwar Europe and postwar Japan.

Eichengreen (1989) notes that prominent British economists and policymakers debated the use of a capital levy in the 1920s when the UK government was suffering from the public debt overhang due to the war debt of World War I. This active debate about the capital levy exemplifies the strength of the ex post temptation for policymakers to introduce a one-

\footnotetext{
${ }^{16}$ For the numerical calculation, we set an upper bound on the value of $b_{t}^{G}$; that is, $\bar{b}^{G}=0.85$. This implies that a lump-sum tax is imposed, when necessary, to keep $b_{t}^{G}$ within the upper bound; hence, this satisfies the transversality condition. The mean of $y_{t}$ is 0.42 , according to the simulation, and thus, $\bar{b}^{G}$ implies that the highest debt-to-GDP ratio is around 2.0, whereas it is around 1.2 (net) currently.

${ }^{17}$ As Gourio $(2012,2013)$ and Isore and Szczerbowicz (2017) argue, the calculation of a trend from data is affected by occasional disasters. However, Japan did not experience a government debt crisis between 1975 and 2019; thus, we do not exclude any sample observations when calculating the trend.
} 
time capital levy when government debt builds up. ${ }^{18}$ Similar debates took place in Italy, Czechoslovakia, Austria, Hungary, Germany, and France. Although Eichengreen concludes that the capital levies in those countries failed, ${ }^{19}$ if history repeats itself or people learn from previous events, these episodes suggest that some people anticipate the capital levy when a crisis strikes. Moreover, post-World War II Japan is a noteworthy example of a successful implementation.

In Japan, the government debt inherited from the wartime period amounted to $267 \%$ of national income in 1944, more than $99 \%$ of which was internal debt (MOF, 1976; Kawamura, 2013). Although Eichengreen (1989) emphasizes that the absolute power of the Supreme Commander for the Allied Powers that occupied Japan was crucial in the successful implementation of the capital levy of 1946-47, the MOF (1976) and Kawamura (2013) show memorandums that prove that it was the MOF that decided to impose a capital levy to avoid an outright default of government debt. The Supreme Commander actually recommended declaring a partial default. The capital levy, or wealth tax, in Japan was a tax on all real and financial assets owned by Japanese residents, including land, houses, government bonds, bank deposits, and machinery. Tax rates varied progressively from $25 \%$ to $90 \%$, depending on the taxpayer's income class. The capital levy worked effectively to reduce wealth inequality among the Japanese. ${ }^{20}$ "With important elements of democracy in suspension, the levy could be quickly and effectively implemented" (Eichengreen, 1989) using the deposit blockade and withdrawing the legal tender status of old yen. The package of these policies, which could not have been implemented in normal times, helped the Japanese government to seize domestic wealth efficiently. ${ }^{21}$

We use this post-war Japanese experience reported by the MOF (1976) to calibrate the parameters of the tax weights $\omega^{i}(i=K, C, G, T)$. The government debt outstanding $(B)$ was 215,867 million yen at the end of 1945 , and the GBO and war indemnity $\left(T^{G}\right)$ were 199,454 million yen (Chapter 11 in the MOF, 1976) and 16,413 million yen (Chapter 7), respectively. The government owed war indemnity because it suspended payments of subsidies, loss compensation, wartime insurance, evacuation costs, and so on. This war indemnity was virtually unpaid, because $100 \%$ of the tax was imposed under the War Indemnity Special Measures Law.

\footnotetext{
${ }^{18}$ Eichengreen (1989) points out that "[i]n modern times, capital levies have come under consideration following every period of major military expenditure and rapidly rising debt/income ratios. (...) None of these proposals was adopted. For examples where capital levies were actually implemented, we must turn to the 20th century."

${ }^{19}$ Eichengreen (1989) finds that Italy and Czechoslovakia were the closest to success. A factor in the failure of the capital levies in these countries was the democratic decision-making processes, because political resistance from property owners led to extreme delays and opportunities for capital flight.

${ }^{20}$ According to the MOF (1976), the main aim of the capital levy was to avoid the default, whereas the Supreme Commander was attempting to reduce inequality. Kawamura (2013) points out that although the super rich class was taxed most heavily, the middle class paid the largest proportion of the total revenue generated by the capital levy.

${ }^{21}$ Saito (2017) points out that the exchange of old yen for new yen was an effective way for the government to seize private assets concealed on the black market. However, note that the tax revenue from the capital levy was less than the amount needed to restore the sustainability of government debt. In contrast, Hattori and Oguro (2016) estimate that the seigniorage revenue resulting from hyperinflation immediately after World War II was nearly $29 \%$ of GDP. However, this large seigniorage revenue was not intended by the government or the MOF officials. Rather, the MOF was concerned about the risk of hyperinflation, as in Germany, which prompted it to introduce the capital levy (MOF, 1976).
} 
The share of the unpaid debt constitutes $\omega^{G}$; thus, we obtain the fraction of the partial default as $\omega^{G}=T^{G} / B=0.076$. The amount of the capital levy $\left(T^{K}\right)$ was 43,500 million yen (Chapter 7 ); thus, we obtain $\omega^{K}=T^{K} / B=0.202$. For $\omega^{C}$, we use the fact that the government increased personal income tax and corporation tax to raise revenues by $T^{C}=3,907$ million yen in 1946 (Chapter 7). Considering that consumption tax plays virtually the same role as income tax, we calculate $\omega^{C}$ as $T^{C} / B=0.018$. Finally, we calibrate $\omega^{T}$ based on the decrease in government expenditure under the government consolidation plan in $1946\left(T^{T}=3,398\right.$ million yen); we find no evidence of an increase in lump-sum tax collection. Then, we obtain $\omega^{T}=T^{T} / B=0.016$.

\subsubsection{Capital-Use Inefficiency in a Crisis}

We calibrate the parameters associated with the capital-use efficiency of production $\lambda_{t}^{Y}$ and depreciation $\lambda_{t}^{D}$. In the former case, we use the database on systemic banking crises from 1970 to 2017 constructed by Laeven and Valencia (2018). We estimate the following equation using the ordinary least squares method:

$$
\frac{\Delta Y_{i}}{Y_{i}}=\theta_{0}+\theta_{1} \xi_{i}+\varepsilon_{i}
$$

where $\Delta Y_{i}$ and $\xi_{i}$ represent the output loss and the ratio of nonperforming loans to total loans, respectively, for crisis episode $i$, and $\varepsilon_{i}$ is a residual. The output loss is measured as the cumulative sum of the differences between the actual and trend real GDP for a period of four years after a crisis, divided by four (i.e., average annual decrease in output). We use 29 of the 151 systemic banking crisis episodes by restricting our estimation to the OECD member countries when a crisis occurred. Figure 5 shows the scatter plot of the results, where each circle indicates a systemic banking crisis episode. The estimates of $\theta_{0}$ and $\theta_{1}$ are 0.062 and 0.154 , respectively; their standard errors are 0.015 and 0.079 , and their p-values are 0.0005 and 0.064, respectively. This suggests that a significant output loss occurs in the event of a banking crisis. Furthermore, the degree of the loss increases as nonperforming loans increase. Combining this result with production function (9) in a crisis, we formulate $\lambda_{t}^{Y}$ as follows:

$$
\lambda_{t}^{Y}=F\left(\xi_{t}\right)=\left(1-\theta_{0}-\theta_{1} \xi_{t}\right)^{1 / \alpha},
$$

where we assume that labor $N_{t}$ is unaffected by the crisis, which is a quantitatively good approximation in our simulation.

We assume that $\lambda_{t}^{D}$ is constant $\left(\lambda_{t}^{D}=\lambda^{D}\right)$, because we are unable to find informative empirical evidence. We determine the parameter value using Japan's Flow of Funds Accounts, compiled by the Bank of Japan. When Japan's systemic banking crisis occurred in 1997 (recorded in Laeven and Valencia, 2018), the liability of non-financial private corporations decreased by $6.074 \% .{ }^{22}$ Considering that this corresponds to a change in the private firms' real firm value, we obtain $\lambda^{D}=1-0.0607$.

\footnotetext{
${ }^{22}$ At the end of March 1997, private bank borrowings and equity were 400 and 375 trillion yen, respectively. At the end of March 1998, they had decreased to 389 and 339 trillion yen, respectively.
} 


\subsubsection{Probability of a Crisis}

We calibrate two parameters associated with the probability of a crisis, $d_{0}$ and $d_{1}$, in equation (1). For domestic debt defaults, empirical data are scarce, as shown by Reinhart and Rogoff (2010). However, as we have discussed in Introduction, several sources of data indicate a mounting concern about a government debt crisis in Japan. Of these, we employ the CDS spread as a target variable to calibrate $d_{0}$ and $d_{1}$, mainly because it can be linked numerically to the probability of a crisis. According to Longstaff et al. (2011), the CDS spread is priced as

$$
C D S=2(1-R) \frac{p}{r+p} \frac{1-e^{-(r+p) / 2}}{e^{-(r+p) / 2}},
$$

where $R, r$, and $p$ represent the recovery rate of government bonds during a crisis, riskless rate, and arrival rate of a crisis, respectively, assuming risk neutrality and constant $r$ and $p$. The spread is approximated as $p(1-R)$ when $r$ and $p$ are sufficiently low. Using this formula, we can calculate the expected value of $p$, and in turn, calibrate $d_{0}$ and $d_{1}$ once we know $R$ and $r$.

Although using the CDS spread is the most straightforward approach to calculating $p$, some caveats are necessary. First, several factors can make the CDS spread divert from the true spread of the underlying bonds, including cash flow differences and liquidity effects (see Longstaff et al., 2011). Second, the above formula is based on risk neutrality. In times of high uncertainty (e.g., the euro crisis around 2010), risk aversion is considered to increase the CDS spread by more than is predicted by the increase in the expected probability of the crisis. Third, the market participants in Japan's sovereign CDSs are mostly foreign traders. Thus, foreign traders may face greater risks, such as the depreciation of yen and the cost of recovery.

Taking these factors into consideration, we calculate the expected value of $p$ as follows. We take the mean of the CDS spreads in two periods before and after the euro crisis: 2003-2006 and 2017-2019. We set the recovery rate of government bonds $R$ to $1-2 \omega^{G}=0.848$, which is slightly smaller than the value of $1-\omega^{G}$ obtained from our model (note that $\omega^{G}$ represents the degree of partial default). ${ }^{23}$ We set the risk-less rate $r$ to $1 /\left(\beta e^{(\nu(1-\psi)-1) \mu}\right)-1 .{ }^{24}$ Substituting the actual CDS values as well as $R$ and $r$ into equation (28), we obtain the probability of a crisis $p$ as 0.05 and 0.14 for the periods 2003-2006 and 2017-2019, respectively.

To target the probability of a crisis $p$, we simulate the variable by changing two parameter values: $d_{0}$ and $d_{1}$. Note that $p$ depends on the government debt-to-GDP ratio $\left(b^{G} / y\right)$, which takes different values for 2003-2006 and 2017-2019. Thus, we simulate $p$ by conditioning the periods in which the simulated ratio $\left(b_{t}^{G} / y_{t}\right)$ falls within the range of the actual or predicted values in 2003-2011 and 2017-2024. ${ }^{25}$ See Section 4.3.1 for the detailed simulation procedure.

\footnotetext{
${ }^{23}$ We find that, with our considerably lower value of $\omega^{G}=0.076$, using $R=1-\omega^{G}$ leads to too high a probability of a crisis ( $p$ can exceed one), around 2010 when the CDS spread jumped. Alternatively, our approach can be interpreted as a way of decomposing the CDS spread into a probability of the crisis occurring and a risk premium component. Longstaff et al. (2011) argue that about two-thirds of the CDS spread variations reflect the probability of a crisis.

${ }^{24}$ The stochastic discount factor equals $M=\beta e^{(\nu(1-\psi)-1) \mu}$ when $x_{t} \tau_{t}^{C}=x_{t+1} \tau_{t+1}^{C}, c_{t}=c_{t+1}, N_{t}=N_{t+1}$, and $e_{t+1}=0$.

${ }^{25}$ The end period is extended by five years, because the CDS has a maturity of five years. The government debt-to-GDP ratio from 2020 to 2024 is calculated by extrapolating from the trend growth rate of 1990-2019.
} 
Table 2 shows the perfect match of the probability of a crisis between the data and the model. We obtain values of $d_{0}=0.003$ and $d_{1}=7$. The former value suggests that the government imposes taxes to reduce its debt about once every 300 years, if government debt is sufficiently low; however, for a high debt, as in 2017-2019, the crisis probability increases to 0.14 .

For robustness, we compare our results with those of other measures of the probability of a crisis. At the one extreme, when we assume a higher recovery rate $\left(R=1-\omega^{G}=0.924\right)$, the probability of a crisis increases to 0.09 and 0.26 for the years of 2003-2006 and 2017-2019, respectively, based on the actual CDS spread data. At the other extreme, we suppose a lower recovery rate $\left(R=1-2 \omega^{G}-\omega^{K}=0.647\right)$, based on the premise that the government declares a larger partial default rather than imposing a capital levy, as in the benchmark model. In this case, the probability of a crisis decreases to 0.02 and 0.07 for the years of 2003-2006 and 2017-2019, respectively. The surveys by Morikawa $(2016,2017)$ show that the average crisis probability from 2016 to 2030 is around $0.02\left(\sim 1-(1-0.25)^{1 / 15}\right.$ years $)$, which is much lower than the value predicted by the model for the same period (0.15). In contrast, Hoshi and Ito (2014) imply that there is a fairly high crisis probability, because the amount of government debt will exceed that of private sector financial assets within 10 years. Our model simulation shows that the probability of a crisis in 2024, 10 years after their study, is 0.23 . This suggests that our benchmark calibration lies between those of Morikawa $(2016,2017)$ and Hoshi and Ito (2014).

\subsection{Simulation Results Based on the Benchmark Model}

\subsubsection{Moments of Variables: Is the Fit of the Model Good?}

In what follows, we discuss two sets of simulation results. The first simulation checks the fit of our model with the data by comparing the key first and second moments of variables such as the mean of the debt-to-output ratio, the standard deviation of the change in consumption, the correlation coefficient between the change in output and the debt-to-output ratio in the previous period, and the correlation coefficient between the change in investment and the credit spread.

Using the model, we calculate the time-series paths of key economic variables. We generate the time-series path of TFP $\left(z_{t}\right)$ for $t=1,2, \cdots, 45$ years. The initial values of the state variables are $b_{0}^{G}=0.05$ for GBO, which is chosen to be constant with the value until 1990, and $k_{0}=0.91$, which is the midpoint of the range of $k$ in our numerical computation. The simulated key economic variables include the debt-to-output ratio $\left(b_{t}^{G} / y_{t}\right)$, the change in log output $\left(\Delta \log Y_{t}\right)$, and the interest-rate spreads $\left(R_{t}^{G}-1\right.$ and $\left.E_{t}\left[R_{t+1}^{K}(0)\right]-R_{t}^{G}\right)$. In addition, we simulate the deposit spread $\left(E_{t}\left[R_{t+1}^{D}(0)\right]-R_{t}^{G}\right)$. The moments are calculated by excluding the crisis periods, because Japan has not experienced a government debt crisis for more than half a century. For the same reason, we calculate the interest rates $R_{t+1}^{K}\left(x_{t+1}\right)$ and $R_{t+1}^{D}\left(x_{t+1}\right)$ in the normal state $\left(x_{t+1}=0\right)$. We set $x_{t}=0$ for $t=1,2, \cdots, 45$; agents in the model are prepared for the risk of a crisis according to equation (1). We repeat this calculation 50 times.

We tabulate the actual moment values for Japan from 1975 to 2019, except for the credit 
and deposit spreads, which run from 1993 to 2019 and 1988 to 2019, respectively. Government debt is expressed in net, not gross from, for $B_{t}^{G}$, except for the figures shown in parentheses. The spread data are the same as those reported in the left-hand panel of Figure 4. The deposit rate is the interest rate on the five-year fixed-term deposit.

Table 3 compares the moments in the actual data with those based on the benchmark model. Although we do not target moments other than $\sigma\left(\Delta \log Y_{t}\right)$, the fit of the model is good. The mean and the standard deviation are of the same order as those in the data. The main caveat seems to be that, in the benchmark model, the mean of the simulated government bond yield, $\left(R_{t}^{G}-1\right)$, is 3.9 percentage points, which is 2.0 percentage points higher than the actual mean. In other words, the actual interest rate is lower than that suggested by the actual TFP growth rate for Japan (see footnote 24). In reality, government bonds act as a medium of exchange, like money, in that they serve as collateral in short-term transactions in the interbank market. This should add a liquidity premium onto the price of government bonds, decreasing the government bond yield. One of the major causes of the discrepancy between the simulated and actual bond yields may be that our model does not consider such a liquidity premium.

Comparing the correlation coefficients, we find that the benchmark model succeeds in explaining the negative coefficients between output growth and both the ratio of GBO (model -0.26 and data -0.30 ) and the credit spread (model -0.21 and data -0.15 ). Furthermore, output growth is positively correlated with the government bond yield (model 0.37 and data 0.28). Investment growth has a similar correlation coefficient with the credit spread and the government bond yield, although that between investment growth and the ratio of GBO is almost zero in the data. According to the model, the deposit spread is negatively correlated with output and investment growth; however, this is not the case in the data.

\subsubsection{Time-series Path: Does the Model Explain the Persistent Stagnation?}

In the second simulation, we generate the time-series paths of the economic variables by assuming an exogenous path of the crisis indicator $x_{t}$. Then, we discuss whether our model can explain Japan's persistent stagnation. Specifically, we assume normal times, $x_{t}=0$, from $t=1$ to 39 years, then a crisis period, $x_{t}=1$, at $t=40$, followed by $x_{t}=0$ thereafter. ${ }^{26}$ Log productivity, $\log z_{t}$, grows with the speed of $\mu$ and no shock $\left(e_{t}=0\right)$. We set the initial value of $b_{t}^{G}$ to 0.05 to match the actual value in 1990. The initial value of $k_{t}$ is set as $k_{0}=k_{S S} e^{0.11}$, where $k_{S S}$ is the steady-state value of capital stock. This is calculated as the mean of the time-series paths of $k_{t}$ obtained using the method in Subsection 4.3.1. The value of $e^{0.11}$ comes from the actual log deviation of the capital stock from its linear trend in 1990, based on the JIP Database 2015.

Figure 6 shows the simulation results. For comparison purposes, we plot the actual paths for Japan from 1990 to 2019 as the solid line with circles. Here, real GDP and investment per capita are shown as deviations from the linear trends of the respective variables from 1975 to

\footnotetext{
${ }^{26}$ The agents in our model do not know this predetermined event; instead, they form expectations on the crisis probability based on equation (1). Thus, the simulated paths do not change until period $t=39$ years, as long as the crisis occurs at $t=40$ or later. The longer the delay before the crisis, the larger the crisis effect will be, because the government introduces larger tax increases.
} 
2019 (see Figure 1). Output $\left(y_{t}\right)$ and investment $\left(i_{t}\right)$ based on the model are detrended by $z_{t}$, and then demeaned so that their average from 1990 to 2019 equals that in the data for the same period. The disaster probability, calculated from the actual CDS spread data, is shown in three lines, corresponding to different assumptions about recovery rate $R: R=1-2 \omega^{G}$ (solid line with circles); $R=1-\omega^{G}$ (dashed line); and $R=1-2 \omega^{G}-\omega^{K}$ (dotted line with asterisks).

The simulated path of the government debt-to-GDP ratio $\left(b_{t}^{G} / y_{t}\right.$; solid line) is similar to the actual path (solid line with circles). This is not surprising because we choose government expenditure $g$ such that the two paths match.

Our model accounts for nearly half the decrease in output $\left(y_{t}\right)$ during the first two decades of the 21st century. Output decreases between 2000 and 2019 as capital investment $\left(i_{t}\right)$ slows down in this period. The model accounts for actual investment during 2000-2019 fairly well. Investment in our model decreases because agents become increasingly cautious about a future crisis, for two reasons. First, the crisis probability increases with the GBO. Second, given the crisis probability, agents anticipate a greater capital tax rate during a crisis $\left(\tau_{t}^{K}\right)$ as the GBO increases, because the government will need greater tax revenue to repay its increased debt. Furthermore, banks' losses at a crisis $\left(\xi_{t}\right)$ increase as the GBO increases, which worsens capital-use efficiency $\left(\lambda_{t}^{Y}\right)$. The higher capital levy and lower capital-use efficiency both lead to an increase in the credit spread $\left(E_{t}\left[R_{t+1}^{K}(0)\right]-R_{t}^{G}\right)$ in normal periods, which discourages investment in capital stock more as the GBO accumulates. ${ }^{27}$ Figure 6 implies that the average annual growth rate of output between 2000 and 2019 is $1.47 \%$ in the model, whereas the trend growth rate of output, $\mu$, is $1.82 \%$. These numbers indicate that output growth slows down as the government's debt accumulates. ${ }^{28}$

Last not the least, the model shows that the bond yield $\left(R_{t}^{G}-1\right)$ decreases rather than increases with the GBO. Although a tax on government bonds is essentially a default, the parameter value of $\omega^{G}$ is low in our benchmark simulation. Thus, agents invest more of their savings in government bonds and less in capital. In other words, Japanese do not anticipate a large-scale government bond default, although they do fear tax increases when a crisis strikes. This pattern is consistent with the Japanese data. The decrease in the bond yield is similar between the data and the model. However, there are caveats. The level of $R_{t}^{G}-1$ based on the model is several percentage points higher than that from the data, as discussed in Section 4.3.1. Moreover, in the model, the increase in the credit spread $\left(E_{t}\left[R_{t+1}^{K}(0)\right]-R_{t}^{G}\right)$ is more sluggish in the first two decades and steeper in the subsequent decade than is suggested by the

\footnotetext{
${ }^{27}$ In the model, we assume, for simplicity, that a crisis ends in one period, unless $x_{t}$ happens to be one in two or more consecutive periods. Our results remain quantitatively similar, even if we assume that a crisis continues for more than one period, as long as distortionary taxes during a crisis have a similar discounted present value. This is a type of the Ricardian equivalence, in that the timing or duration of a tax imposition does not affect the ex ante slowdown in investment and output, as long as the total tax distortion remains the same.

${ }^{28}$ In our model, output increases during the 1990s when the GBO is low. This is driven by an increase in consumption. In the 1990s, the probability of a crisis is low and, even if a crisis occurs, the resulting distortion caused by the capital levy and capital-use inefficiency is small. As a result, the household chooses to consume in the current period rather than save. In reality, the decrease in actual output during the 1990s might have been caused by factors external to our model, such as the collapse of the asset-price bubble in the early 1990s and the subsequent decade-long period of financial distress.
} 
data.

\subsection{Differing Expectations about Tax Scenarios in the Crisis Period}

In the benchmark model, we assumed tax weights of $\omega^{K}=0.202, \omega^{C}=0.018, \omega^{G}=0.076$, and $\omega^{T}=0.016$ as the governmental tax policy following a government debt crisis. In this subsection, we investigate how the simulation results change when Japanese people have differing expectations about tax scenarios at the point of the crisis. This exercise helps understand the underlying transmission mechanism caused by the taxes. The results are shown in Figures 6 and 7.

We consider a first-best case in which the government imposes a lump-sum tax $\left(T_{t}\right)$ only. The size of the tax collection is the same as that in the benchmark case, namely $\omega^{T}=0.312$. Because banks remain solvent, bank runs do not occur, and capital use is efficient (i.e., $\lambda^{Y}=$ $\lambda^{D}=1$ ). This hypothetical case partly reflects a decrease in government transfers (e.g., a decrease in pension obligations or medical care) during a crisis. "All T tax" in Figure 6 shows that there is almost no change in real economic activity as the GBO increases. Slight changes occur because the capital stock starts from $k_{0}=k_{S S} e^{0.11}$. Note that the growth rate of the debt ratio $\left(b_{t}^{G} / y_{t}\right)$ slows down, because output no longer decreases.

In order to investigate the effects of various taxes independently, we set the tax weight, $\omega^{i}(i=K, C, G)$, at zero, one by one, and simulate the time-series paths of the economic variables. By the size of the decrease in $\omega^{i}$, the value of $\omega^{T}$ increases to maintain the total amount of tax collected during a crisis. The results are shown in Figure 7 . When we eliminate the capital levy during the crisis ("No K tax" in the figure), the decreases in output and investment are greatly mitigated, and the credit spread $\left(E_{t}\left[R_{t+1}^{K}(0)\right]-R_{t}^{G}\right)$ hardly increases. In this scenario, the capital use during the crisis remains inefficient $\left(\lambda^{Y}, \lambda^{D}<1\right)$, which contributes to a decrease in investment. However, the figure suggests that the contribution of capital-use inefficiency is quantitatively much smaller than that of the capital levy. The capital-use efficiency for output $\left(\lambda_{t}^{Y}\right)$ deteriorates only slightly, because the ratio of banks' nonperforming loans does not increase much without the capital levy.

"No G tax" in Figure 7 shows that eliminating the tax on GBO during a crisis causes little change, particularly before 2010. However, the loss of fear of a government bond default decreases the government bond yield, which slows the accumulation of the debt ratio. This reduces the crisis probability compared with that of the benchmark model, which mitigates the output stagnation after 2010. "No C tax" in the figure shows that eliminating the consumption tax during a crisis does not alter our simulation results considerably. In our calibration, both $\omega^{C}$ and $\omega^{G}$ are small, and thus, their effects are quantitatively limited.

There are many alternatives to the tax policies considered above. One of the most realistic options is an income tax, imposed on the return on capital (e.g., $E_{t}\left[R_{t+1}^{K}(0)\right]-1$ in our model), return on government bonds (e.g., $R_{t}^{G}-1$ ), or labor income (e.g., $W_{t} N_{t}$ ). However, such taxes on incomes (flow variables) are insufficient to repay government debt because their revenue cannot exceed the incomes. Thus, expectations of income taxes have small quantitative effects on pre-crisis output. Qualitatively, the effect of a capital income tax is similar to that of a capital levy, and the effect of a tax on the interest on government bonds is similar to that on 
GBO. The effect of a labor income tax is similar to that of a consumption tax, both qualitatively and quantitatively.

\section{$5 \quad$ Further Analyses}

\subsection{A Smaller Loss of Capital-Use Efficiency}

In our model, Japan's persistent stagnation is caused by two main expectations: the capital levy and the capital-use inefficiency at the time of the crisis. In Figure 8, we simulate the paths of the economic variables when we decrease the latter. First, we assume no additional capital depreciation during the crisis (i.e., $\lambda^{D}=1$ ), and we keep the production inefficiency $\left(\lambda_{t}^{Y}\right)$ at the same value as the benchmark. The dotted line shows that the credit spread falls by around 0.5 percentage points. This worsens the fit of the model in terms of the first moment of the credit spread. However, it does not affect the changes in output and investment before the crisis. We observe an increase, rather than a decrease, in output one period after the crisis occurs, because, in this case, the crisis does not depreciate capital.

Second, in addition to $\lambda^{D}=1$, we assume constant $\lambda_{t}^{Y}=0.95$. The simulated paths, shown as solid lines, are almost the same as those shown as dotted lines. The only difference is that output no longer drops when the crisis occurs. Therefore, we conclude that the persistent stagnation is caused mainly by the expectation of a large-scale capital levy during a crisis.

\subsection{A Smaller Probability of a Crisis}

We examine the robustness of our results to changes in the parameters associated with the crisis probability, $d_{0}$ and $d_{1}$, in Figure 9 . We assume a lower crisis probability, such that the probability at the time of no government debt, $d_{0}$, decreases from 0.003 to 0.002 , and the sensitivity of the probability to government debt, $d_{1}$, decreases from 7.0 to 5.5 . It should be noted that these values are inconsistent with the observed CDS spread if we assume the same recovery rate, $R=1-2 \omega^{G}$. Thus, to maintain consistency with the CDS spread, we assume a lower recovery rate, $R=1-2 \omega^{G}-\omega^{K}=0.647$.

The solid line shows the simulation results. The agents face a smaller crisis risk. This makes the changes in output, investment, bond yield, credit spread, and probability of a crisis smaller by about a half compared with the benchmark model.

When the crisis probability decreases in the above manner, it would be more plausible to assume that $\omega^{G}$ increases, because we assume a lower recovery rate $R$. Thus, we set $\omega^{K}$ at zero, and instead increase $\omega^{G}$. In other words, Japanese people expect a larger government bond default $\left(\omega^{G}=0.278\right)$ in exchange for eliminating the capital levy $\left(\omega^{K}=0\right)$. The government is assumed to declare a default for about a quarter of the GBO. The values of $d_{0}$ and $d_{1}$ are 0.002 and 5.5, respectively. The dotted line in the figure shows the simulation result. Under this scenario, the government bond yield increases from the mid-2000s as government debt increases, which is opposite to what actually happened in Japan. Investing in capital becomes less risky than investing in government bonds. As a result, the credit spread $\left(E_{t}\left[R_{t+1}^{K}(0)\right]-R_{t}^{G}\right)$ decreases, rather than increases, and capital investment decreases only slightly. 


\subsection{Welfare}

Using the model, we calculate the loss in welfare. We generate time-series paths for the TFP $\left(z_{t}\right)$ and crisis indicator $\left(x_{t}\right)$ randomly for 1000 years, discard the first one-third samples, and take the mean. A welfare loss can arise from not only the expectation of a crisis before it occurs but also the distortion at the time of the crisis. Thus, we calculate the welfare loss by including crisis periods, unlike the simulation conducted in Section 4.3. Table 4 shows the simulation result. Output $\left(y_{t}\right)$ and welfare $\left(U_{t}\right.$, in terms of consumption equivalence) are indicated as differences from the values in the benchmark model. ${ }^{29}$ The mean debt-to-output ratio increases to 1.37 in the benchmark model when we extend the simulation from 25 to 1000 years.

If the tax is not distortionary ("All $\mathrm{T}$ tax"), both output and welfare improve by $19 \%$ and $7 \%$, respectively. These large improvements are the result of a non-distortionary tax and capital-use efficiency. Of the distortionary taxes, the capital levy is the most important, contributing to the decreases in output and welfare by $12 \%$ and $2 \%$, respectively. The tax on GBO plays the second most important role, decreasing output and welfare by $5 \%$ and $1 \%$, respectively.

Capital-use inefficiency seems to influence welfare more than distortionary taxes do. When we set $\lambda_{t}^{Y}=0.95$ and $\lambda^{D}=1$, output and welfare improve by $10 \%$ and $5 \%$, respectively. In summary, capital-use inefficiency explains about two-thirds of the welfare improvement in the "All T tax" scenario. Figure 8 shows that capital-use inefficiency alone is unable to explain Japan's persistent stagnation. However, this result shows that capital-use inefficiency is important, and thus should not be ignored, when determining the implications for welfare.

\subsection{Permanent Distortionary Tax to Prevent a Crisis from Occurring}

Should a government raise tax rates in normal times to avoid a crisis? Because a crisis event causes not only a depression at the time but also stagnation beforehand, it may be better to introduce higher tax rates preemptively. To answer this question, we consider a model in which the government always aims to maintain a bounded range of government debt. Specifically, we assume the following tax policy:

$$
\begin{aligned}
\tau_{t}^{C} & =\max \left(0, \min \left(\tau_{t}^{C *}, 0.3\right)\right), \\
\tau_{t}^{C *} & =\left(1-\frac{b^{G}}{b_{t}^{G}+g} q_{t}^{G} e^{\mu}\right) \frac{b_{t}^{G}+g}{c_{t}} .
\end{aligned}
$$

The government imposes a consumption tax only in order to maintain $b_{t+1}^{G}$ around its target $b^{\bar{G}}$, where the maximum tax rate for $\tau_{t}^{C}$ is $30 \%$, and the target $\bar{b}^{\bar{G}}$ is set at $0.3 .^{30}$

\footnotetext{
${ }^{29}$ Welfare in terms of consumption equivalence is measured as follows. We calculate lifetime utility in the case in question and the benchmark case. We then determine the permanent percentage increase in consumption needed in the benchmark case such that the households will be indifferent between the two cases. This permanent increase is the consumption equivalence.

${ }^{30}$ Because the future TFP shock $e_{t+1}$ is unknown, the government cannot perfectly stabilize $b_{t+1}^{G}$ at its target. In our numerical calculation, we set an upper bound $b^{U}$ for $b_{t}^{G}$, where $b^{U} \gg \bar{b}^{G}$, and impose a lump-sum tax only when the consumption tax alone cannot maintain $b_{t+1}^{G} \leq b^{U}$.
} 
Table 4 shows the simulation results. The bottom row shows that the debt ratio $\left(b^{G} / y\right)$ stabilizes at $70 \%$, and that output increases by $11 \%$. As a result, welfare increases by $5 \%$ in the consumption unit. Therefore, preemptive tax increases improve social welfare. ${ }^{31}$

\subsection{Final Thoughts on Government Tax Policy}

Given the results on welfare, one may think that the Japanese government will (or should) not adopt a capital levy, but should instead use a costless lump-sum tax if a government debt crisis occurs. Moreover, one may wonder why the Japanese government does not raise taxes now, before a crisis occurs. In the final part of this study, we discuss several issues related to government policy, although our model cannot address these questions formally because it does not endogenize government actions.

With regard to the tax policy during a crisis, three points are worth making. First, as noted in Section 4.2.1, the post-war Japanese government did not resort to a lump-sum tax, but instead imposed a heavy capital levy. Second, a capital levy has political apeal because it is effective at reducing wealth inequality, as demonstrated in post-war Japan (Eichengreen, 1989). In contrast, a lump-sum tax hurts the poor relatively more than it does the rich. Third, as noted by Eichengreen (1989) as well as Chamley (1986) and Chari, Christiano, and Kehoe (1994), a once-and-for-all capital levy has no distortionary effect on economic activity ex post facto, although this point applies to a lump-sum tax as well.

With regard to the tax policy before a crisis, a possible reason for the Japanese government not trying to decrease its debt today by raising the tax rate may be the short time horizon of its perspective. Parliament elections for upper and lower houses are held at least every three years. Thus, if the government does not believe a crisis will occur in the near future, it has little incentive to raise taxes, because doing so hurts utility in the short run. Indeed, Prime Minister Shinzo Abe postponed a promised increase in the consumption tax rate from $8 \%$ to $10 \%$ twice, in 2014 and 2016.

\section{Concluding Remarks}

We have analyzed an economy at risk of a government debt crisis, and provided a new perspective to explain the secular stagnation and low interest rates that occur. We have demonstrated that most of the persistent slowdown in economic growth can be accounted for by the increasing fear of a capital levy and misallocations of capital associated with the increasing government debt.

Because our framework is simple, it can be extended and enriched in numerous ways. One possibility is to introduce nominal variables (e.g., Aguiar et al., 2015). The nominal version of our model would be useful for analyzing price dynamics, such as hyperinflation, and the implications for monetary policy in the event of secular stagnation with deflation. Importantly,

\footnotetext{
${ }^{31} \mathrm{An}$ alternative approach is to calculate lifetime utility at $t$, conditional on the state in which the debt-to-GDP ratio, $b_{t-1}^{G} / y_{t-1}$, is as high as it is today. We confirm that this hardly changes our results. Because discount factor $\beta$ in our model is close to one, the household is concerned about the long-run state of the economy, rather than its short-run transition, even if a high debt ratio induces a very high temporary consumption tax rate.
} 
inflation is essentially equivalent to a tax on GBO (i.e., a default), because inflation decreases the real value of nominal bonds directly, whereas it does not affect the real value of capital much. Thus, we believe our analysis of a tax on GBO approximates the effects of high inflation in a nominal model. A second possibility would be to open the economy, such that policy implications can be altered by the interaction between domestic and external debt as well as the incentive for capital flight. In fact, during Japan's lost decades, Japanese firms have increased their levels of foreign direct investment, which can be analyzed properly in an openeconomy model. Third, our model can be extended to incorporate uncertainty during a crisis. A crisis usually entails a large degree of uncertainty in the market and government responses, which may quantitatively alter our results. Lastly, it would be worth extending our model to include heterogeneous agents. As such, when a crisis occurs, taxes on capital stock and government bonds can influence the holdings of both assets, which plays an important role in the self-insurance of heterogeneous households.

These extensions may help us explore whether the increasing risk of a crisis causes other economic difficulties in addition to the persistent stagnation demonstrated in this study.

\section{References}

[1] Aguiar, Mark, and Manuel Amador (2011), "Growth in the Shadow of Expropriation," Quarterly Journal of Economics, 126(2), 651-697.

[2] Aguiar, Mark, Manuel Amador, Emmanuel Fahri, and Gita Gopinath (2015), "Coordination and Crisis in Monetary Unions," Quarterly Journal of Economics, 130(4), 1727-1779.

[3] Aguiar, Mark, Manuel Amador, and Gita Gopinath (2009), "Investment Cycles and Sovereign Debt Overhang," Review of Economic Studies, 76, 1-31.

[4] Alesina, Alberto, and Silvia Ardagna (1998), "Tales of Fiscal Adjustments," Economic Policy 13(27), 489-545.

[5] Alesina, Alberto, and Roberto Perotti (1996), "Reducing Budget Deficits," Swedish Economic Policy Review, 3, 113-34.

[6] Arellano, Cristina (2008), "Default Risk and Income Fluctuations in Emerging Economies," American Economic Review, 98(3), 690-712.

[7] Arellano, Cristina, Yan Bai, and Gabriel Mihalache (2018), "Default Risk, Sectoral Reallocation, and Persistent Recessions," Journal of International Economics, 112, 182-199.

[8] Balke, Neele (2017), "The Employment Cost of Sovereign Default," draft.

[9] Barro, Robert J. (2006), "Rare Disasters and Asset Markets," Quarterly Journal of Economics, 121(3), 823-866.

[10] Barro, Robert J. (2009), "Rare Disasters, Asset Prices, and Welfare Costs," American Economic Review, 99, 243-264. 
[11] Barro, Robert J., and Xavier Sala-i-Martin (1995), Economic Growth, New York: McGrawHill, 2nd edition.

[12] Baum, Anja, Cristina Checherita-Westphal, and Phillip Rother (2013), "Debt and Growth: New Evidence for the Euro Area," Journal of International Money and Finance, 32, 809821.

[13] Benigno, Gianluca and Luca Fornaro (2018), "Stagnation Traps," Review of Economic Studies, 85(3), 1425-1470.

[14] Bianchi, Javier, Juan Carlos Hatchondo, and Leonardo Martinez (2018), "International Reserves and Rollover Risk," American Economic Review, 108(9), 2629-2670.

[15] Bocola, Luigi (2016), "The Pass-Through of Sovereign Risk," Journal of Political Economy, $124(4), 879-926$.

[16] Bohn, Henning (1998), "The Behavior of U.S. Public Debt and Deficits," Quarterly Journal of Economics, 113(3), 949-963.

[17] Caballero, Ricardo, Takeo Hoshi, and Anil Kashyap (2008), "Zombie Lending and Depressed Restructuring in Japan," American Economic Review, 98, 1943-1977.

[18] Caballero, Ricardo, and Alp Simsek (2017), "A Risk-centric Model of Demand Recessions and Macroprudential Policy," MIT mimeo.

[19] Chamley, Christophe (1986), "Optimal Taxation of Capital Income in General Equilibrium with Infinite Lives," Econometrica, 54, 607-22.

[20] Chari, V. V., Lawrence J. Christiano, and Patrick J. Kehoe (1994), "Optimal Fiscal Policy in a Business Cycle Model," Journal of Political Economy, 102(4), 617-652.

[21] Checherita-Westphal, Cristina, and Phillip Rother (2012), "The Impact of High Government Debt on Economic Growth and its Channels: An Empirical Investigation for the Euro Area," European Economic Review, 56(7), 1392-1405.

[22] Cole, Harold L. and Timothy J. Kehoe (2000), "Self-Fulfilling Debt Crises," Review of Economic Studies, 67(1), 91-116.

[23] D'Erasmo, Pablo, and Enrique G. Mendoza (2016), "Optimal Domestic (and External) Sovereign Default." NBER Working Paper 22509, National Bureau of Economic Research.

[24] Eggertsson, Gauti, Neil Mehrotra, and Jacob Robbins (2019), "A Model of Secular Stagnation: Theory and Quantitative Evaluation," American Economic Journal: Macroeconomics, 11(1), 1-48.

[25] Eichengreen, Barry (1989), "The Capital Levy in Theory and Practice," NBER Working Paper 3096. 
[26] Fischer, Stanley (1991), "Growth, Macroeconomics, and Development," in Olivier Jean Blanchard and Stanley Fischer (ed), NBER Macroeconomics Annual, Vol. 6, Cambridge, MA: MIT Press, pp. $75-122$.

[27] Gabaix, Xavier (2012), "Variable Rare Disasters: An Exactly Solved Framework for Ten Puzzles in Macro-Finance," Quarterly Journal of Economics, 127(2), 645-700.

[28] Giavazzi, Francesco, and Marco Pagano (1990), "Can Severe Fiscal Adjustments Be Expansionary?" in NBER Macroeconomics Annual 1990, Oliver Blanchard and Stanley Fischer, eds., Cambridge, MA: MIT Press.

[29] Gordon, Robert J. (2012), "Is U.S. Economic Growth Over? Faltering Innovation Confronts the Six Headwinds," NBER Working Papers 18315.

[30] Gourio, Francois (2012), "Disaster Risk and Business Cycles." American Economic Review, 102(6), 2734-66.

[31] Gourio, Francois (2013), "Credit Risk and Disaster Risk," American Economic Journal: Macroeconomics, 5(3), 1-34.

[32] Hansen, Alvin H. (1939), "Economic Progress and Declining Population Growth," American Economic Review, 29, 1-15.

[33] Hattori, Takahiro and Kazumasa Oguro (2016), "An Endeavor to Estimate Seigniorage before the End of and Immediately after the Pacific War," Journal of The Japanese and International Economies, 41, 1-16.

[34] Hayashi, Fumio, and Edward C. Prescott (2002), "The 1990 in Japan: A Lost Decade," Review of Economic Dynamics, 5, 206-235.

[35] Hirose, Yasuo, and Takushi Kurozumi (2012), "Do Investment-Specific Technological Changes Matter for Business Fluctuation? Evidence from Japan," Pacific Economic Review, 17(2), 208-230.

[36] Hoshi, Takeo, and Takatoshi Ito (2014), "Defying Gravity: Can Japanese Sovereign Debt Continue to Increase Without a Crisis?" Economic Policy, 29(77), 5-44.

[37] Isore, Marlene, and Urszula Szczerbowicz (2017), "Disaster Risk and Preference Shifts in a New Keynesian Model," Journal of Economic Dynamics and Control, 79, 97-125.

[38] Kawamura, Sayuri (2013), "How to Take on Fiscal Consolidation (in Japanese)," Japan Research Institute (JRI) Review, 8(9), 49-79.

[39] Kozlowski, Julian, Laura Veldkamp, and Venky Venkateswaran (2015), "The Tail that Wags the Economy: The Origin of Secular Stagnation," NBER Working Paper No. 21719.

[40] Krugman, Paul (2013), "Secular Stagnation, Coalmines, Bubbles, and Larry Summers," New York Times (November 16). 
[41] Kunieda, Shigeki (2015), "Fiscal Policy in Rare Disaster Models: Bohn meets Barro in Japan," draft.

[42] Laeven Luc and Fabian Valencia (2018), "Systematic Banking Crises Revisted," IMF Working Paper 18/206.

[43] Lo, Stephanie, and Kenneth Rogoff (2015), "Secular Stagnation, Debt Overhang and Other Rationales for Sluggish Growth, Six Years on," BIS Working Papers No. 482, Bank for International Settlements.

[44] Longstaff, Francis A., Jun Pan, Lasse H. Pedersen, and Kenneth J. Singleton (2011), "How Sovereign Is Sovereign Credit Risk?" American Economic Journal: Macroeconomics, 3(2), $75-103$.

[45] Ministry of Finance (1976), "Showa History of Fiscal Policy (in Japanese)," Tokyo: Toyo Keizai.

[46] Morikawa, Masayuki (2016), "How Uncertain Are Economic Policies? Evidence from a Survey on Japanese firms." RIETI Policy Discussion Paper Series 16-P-008, Research Institute of Economy, Trade and Industry.

[47] Morikawa, Masayuki (2017), "Policy Uncertainty and Consumption and Savings Behavior (in Japanese)" RIETI Discussion Paper Series 17-J-007, Research Institute of Economy, Trade and Industry.

[48] Perotti, Roberto (1999), "Fiscal Policy in Good Times and Bad," Quarterly Journal of Economics, 114(4), 1399-436.

[49] Reinhart, Carmen M., Vincent R. Reinhart, and Kenneth S. Rogoff (2012), "Public Debt Overhangs: Advanced-Economy Episodes since 1800," Journal of Economic Perspectives, 26(3), 69-86.

[50] Reinhart, Carmen M., and Kenneth S. Rogoff (2010), "Growth in a Time of Debt," American Economic Review: Papers 8 Proceedings, 100.

[51] Rietz, Thomas A. (1988), "The Equity Premium Puzzle: A Solution," Journal of Monetary Economics, 22, 117-131.

[52] Saito, Makoto (2017), "On Large-Scale Money Finance in the Presence of Black Markets: The Case of the Japanese Economy during and after World War II," draft.

[53] Sakuragawa, Masaya, and Yukie Sakuragawa (2016), "Absence of Safe Assets and Fiscal Crisis," Journal of the Japanese and International Economies, 40: 59-76.

[54] Sugo, Tomohiro, and Kozo Ueda (2008) "Estimating a Dynamic Stochastic General Equilibrium Model for Japan," Journal of the Japanese and International Economies, 22, 476502. 
[55] Summers, Lawrence (2013), "Why Stagnation Might Prove to be the New Normal," The Financial Times (December 16). 


\section{A Model Details}

We denote the variables divided by $z_{t}$ by their lower case letters (e.g., $y_{t} \equiv Y_{t} / z_{t}$ ), with the exception of $u_{t} \equiv U_{t}^{1-\psi} / z_{t}^{\nu(1-\psi)}$. In summary, we have 16 equations for 16 unknown endogenous variables $\left\{c_{t}, k_{t}, N_{t}, y_{t}, M_{t+1}, u_{t}, x_{t}, \lambda_{t}^{Y}, q_{t}^{G}, R_{t}^{K}, R_{t}^{D}, b_{t}^{G}, \tau_{t}^{K}, \tau_{t}^{C}, \tau_{t}^{G}, t_{t}\right\}$ :

$$
\begin{aligned}
& (1-\alpha) \frac{y_{t}}{N_{t}}=\frac{1-\nu}{\nu} \frac{\left(1+x_{t} \tau_{t}^{C}\right) c_{t}}{1-N_{t}}, \\
& 1=E_{t}\left[M_{t+1} R_{t+1}^{D}\left(x_{t+1}\right)\right], \\
& R_{t+1}^{D}\left(x_{t+1}\right)=\frac{\left(1-x_{t+1} \tau_{t+1}^{K}\right) R_{t+1}^{K}\left(x_{t+1}\right) K_{t+1}+\left(1-x_{t+1} \tau_{t+1}^{G}\right) B_{t+1}^{G}}{K_{t+1}+q_{t}^{G} B_{t+1}^{G}}, \\
& E_{t}\left[M_{t+1}\left(1-x_{t+1} \tau_{t+1}^{K}\right) R_{t+1}^{K}\left(x_{t+1}\right)\right]=\frac{1}{q_{t}^{G}} E_{t}\left[M_{t+1}\left(1-x_{t+1} \tau_{t+1}^{G}\right)\right], \\
& R_{t}^{K}=(1-\delta)\left(x_{t} \lambda^{D}+1-x_{t}\right)+\alpha \frac{y_{t}}{k_{t}}, \\
& y_{t}=\left(x_{t} \lambda_{t}^{Y}+\left(1-x_{t}\right)\right)^{\alpha}\left(k_{t}\right)^{\alpha} N_{t}^{1-\alpha}, \\
& M_{t+1}=\beta\left(\frac{1+x_{t} \tau_{t}^{C}}{1+x_{t+1} \tau_{t+1}^{C}}\right) e^{(\nu(1-\psi)-1)\left(\mu+\sigma_{e} e_{t+1}\right)}\left(\frac{c_{t+1}}{c_{t}}\right)^{\nu(1-\psi)-1}\left(\frac{1-N_{t+1}}{1-N_{t}}\right)^{(1-\nu)(1-\psi)} \\
& u_{t}=(1-\beta) c_{t}^{\nu(1-\psi)}\left(1-N_{t}\right)^{(1-\nu)(1-\psi)}+\beta E_{t}\left(e^{\nu(1-\psi)\left(\mu+\sigma_{e} e_{t+1}\right)} u_{t+1}\right) \text {, } \\
& y_{t}=c_{t}+k_{t+1} e^{\mu+\sigma_{e} e_{t+1}}-(1-\delta)\left(x_{t} \lambda^{D}+1-x_{t}\right) k_{t}, \\
& \operatorname{Pr}\left(x_{t+1}=1 \mid b_{t}^{G}\right)=\frac{1}{1+\left(1 / d_{0}-1\right) \exp \left(-d_{1} b_{t}^{G}\right)} \\
& q_{t}^{G} b_{t+1}^{G} e^{\mu+\sigma_{e} e_{t+1}}+x_{t} \tau_{t}^{C} c_{t}+x_{t} \tau_{t}^{K} k_{t} \\
& +x_{t} \tau_{t}^{G} b_{t}^{G}+x_{t} t_{t}=b_{t}^{G}+g, \\
& \tau_{t}^{K} R_{t}^{K} K_{t}=\omega^{K}\left(b_{t}^{G}+g\right), \\
& \tau_{t}^{C} c_{t}=\omega^{C}\left(b_{t}^{G}+g\right) \text {, } \\
& \tau_{t}^{G} b_{t}^{G}=\omega^{G}\left(b_{t}^{G}+g\right), \\
& t_{t}=\omega^{T}\left(b_{t}^{G}+g\right),
\end{aligned}
$$

where $\lambda_{t}^{Y}$ is given by equation (15) and $e_{t}$ follows $N(0,1)$. 


\section{B Two-period Model}

Given the prices $\left(R^{K}(x), W(x)\right)$, the solution to the period 1 problem is given by

$$
\begin{aligned}
& N_{1}(x, K, B)=\nu-\left\{\left(1-x \tau^{K}\right) R^{K}(x) K+\left(1-x \tau^{G}\right) B-x T-(1-x) \tilde{T}\right\} \frac{(1-\nu)}{W(x)}, \\
& C_{1}(x, K, B)=\nu\left[W(x)+\left(1-x \tau^{K}\right) R^{K}(x) K+\left(1-x \tau^{G}\right) B-x T-(1-x) \tilde{T}\right] .
\end{aligned}
$$

Because the first-order condition for the period 1 problem implies that $C_{1}^{\nu}\left(1-N_{1}\right)^{1-\nu}=$ $\left(\frac{1-\nu}{\nu W(x)}\right)^{(1-\nu)} C_{1}$, the period 0 problem is rewritten as

$$
\max _{C_{0}, N_{0}, K, B}(1-\beta)\left\{C_{0}^{\nu}\left(1-N_{0}\right)^{1-\nu}\right\}^{1-\psi}+\beta E_{0}\left\{\left[\left(\frac{1-\nu}{\nu W(x)}\right)^{1-\nu} C_{1}(x, K, B)\right]^{1-\psi}\right\},
$$

subject to (25). The first-order conditions with respect to $K$ and $B$ imply

$$
\begin{aligned}
& \lambda=\beta(1-\psi)\left(\frac{1-\nu}{\nu}\right)^{1-\nu}\left\{p(B) \frac{\left(1-\tau^{K}\right) R^{K}(1)}{W(1)^{(1-\nu)(1-\psi)} C_{1}(1)^{\psi}}+(1-p(B)) \frac{R^{K}(0)}{W(0)^{(1-\nu)(1-\psi)} C_{1}(0)^{\psi}}\right\}, \\
& q \lambda=\beta(1-\psi)\left(\frac{1-\nu}{\nu}\right)^{1-\nu}\left\{p(B) \frac{\left(1-\tau^{G}\right)}{W(1)^{(1-\nu)(1-\psi)} C_{1}(1)^{\psi}}+(1-p(B)) \frac{1}{W(0)^{(1-\nu)(1-\psi)} C_{1}(0)^{\psi}}\right\},
\end{aligned}
$$

where $\lambda$ is the Lagrange multiplier for $(25)$ and $p(B)$ is the probability that a crisis occurs, which is increasing in $B$.

Now, we can calculate the equilibrium by combining the above solutions to the household problem and those to the firm's problem. For simplicity of exposition, we assume that $\delta=1$ and $\tau^{C}=0$. Given these parameter values, we have the following equilibrium values:

$$
\begin{aligned}
& N_{0}=N_{1}(0)=N_{1}(1)=\frac{(1-\alpha) \nu}{1-\alpha \nu} \equiv \bar{n}, \\
& C_{0}=K_{0}^{\alpha}(z \bar{n})^{1-\alpha} \equiv \bar{c} K_{0}^{\alpha}, \\
& C_{1}(0)=C_{1}(1)=\bar{c} K^{\alpha}, \\
& W(0)=W(1)=\frac{(1-\nu) \bar{c} K^{\alpha}}{\nu(1-\bar{n})} \equiv \bar{w} K^{\alpha}, \\
& R^{K}(0)=R^{K}(1)=\alpha\left(\frac{z \bar{n}}{K}\right)^{1-\alpha} \equiv \bar{r} K^{\alpha-1},
\end{aligned}
$$

where $\bar{n}, \bar{c}, \bar{w}$, and $\bar{r}$ are constant. The equilibrium value of the Lagrange multiplier $\lambda$ is determined by $\lambda=(1-\beta)(1-\psi) \nu C_{0}^{\nu(1-\psi)-1}\left(1-N_{0}\right)^{(1-\nu)(1-\psi)}$, which is constant, given that $K_{0}$ is constant. Thus, denoting it by $\bar{\lambda}$, we can derive the following equilibrium conditions from (45) and (46):

$$
\begin{aligned}
& K=\left[\frac{\beta(1-\psi) \bar{r}}{\bar{\lambda} \bar{c} \psi}\left(\frac{1-\nu}{\nu \bar{w}}\right)^{(1-\nu)(1-\psi)}\left\{p(B)\left(1-\tau^{K}\right)+1-p(B)\right\}\right]^{\frac{1}{1-(1-\psi) \alpha \nu}}, \\
& q=\frac{\beta(1-\psi)}{\bar{\lambda} \bar{c} \psi}\left(\frac{1-\nu}{\nu \bar{w}}\right)^{(1-\nu)(1-\psi)} \frac{\left\{p(B)\left(1-\tau^{G}\right)+1-p(B)\right\}}{K^{(1+\psi) \alpha}}
\end{aligned}
$$


For simplicity, we further assume $\tau^{G}=0$, which implies that

$$
q=\frac{\beta(1-\psi)}{\bar{\lambda} \bar{c} \psi}\left(\frac{1-\nu}{\nu \bar{w}}\right)^{(1-\nu)(1-\psi)} K^{-(1+\psi) \alpha} .
$$

The equilibrium value of $B$ is given by the government budget in period 0 , that is,

$$
q B=G+B_{0}
$$

Conditions (47), (48), and (49) determine the equilibrium. Because $p(B)$ is increasing in $B$, (47) implies that $K$ is decreasing in $B$, and (48) implies that $q$ is increasing in $B$. Thus, (49) implies that $B$ is increasing in $B_{0}$. 
Table 1: Calibrated Parameters

\begin{tabular}{|c|c|c|}
\hline Parameters & Values & Sources \\
\hline Capital share $\alpha$ & 0.3 & Gourio (2013) \\
\hline Discount factor $\beta$ & 0.995 & Sugo and Ueda (2011) \\
\hline Utility weight on $C \nu$ & 0.3 & Gourio (2013) \\
\hline IES utility $\psi$ & 1.5 & Sugo and Ueda (2008); Hirose and Kurozumi (2012) \\
\hline Depreciation $\delta$ & 0.08 & Gourio (2013) \\
\hline Trend growth of TFP $\mu$ & 0.0182 & Mean of $\Delta \log Y_{t}$ \\
\hline SD of TFP shock $\sigma_{e}$ & 0.023 & $\mathrm{SD}$ of $\Delta \log Y_{t}$ \\
\hline Gov spending $g$ & 0.02 & Mean of $\Delta\left(b_{t}^{G} / y_{t}\right)$ \\
\hline Tax weights & & \\
\hline capital levy $\omega^{K}$ & 0.2015 & Post-war Japan \\
\hline consumption $\operatorname{tax} \omega^{C}$ & 0.0181 & Post-war Japan \\
\hline government bonds (default) $\omega^{G}$ & 0.0760 & Post-war Japan \\
\hline lump-sum tax $\omega^{T}$ & 0.0157 & Post-war Japan \\
\hline \multicolumn{3}{|l|}{ Capital-use inefficiency } \\
\hline production $\theta_{0}$ & 0.062 & Laeven and Valencia (2018) \\
\hline production; dependence on bad loans $\theta_{1}$ & 0.154 & Laeven and Valencia (2018) \\
\hline depreciation $\lambda^{D}$ & $1-0.061$ & Flow of Funds in 1997 and 1998 \\
\hline \multicolumn{3}{|l|}{ Crisis probability } \\
\hline at $b=0 d_{0}$ & 0.003 & CDS spreads and $\omega^{G}$ \\
\hline dependence on $b d_{1}$ & 7.0 & CDS spreads and $\omega^{G}$ \\
\hline
\end{tabular}


Table 2: The Probability of a Crisis

\begin{tabular}{lccc} 
Target & & Data & Model \\
\hline CDS 2003-06 & $R=1-2 \omega^{G}$ & 0.05 & 0.05 \\
& $R=1-\omega^{G}$ & 0.09 & \\
& $R=1-2 \omega^{G}-\omega^{K}$ & 0.02 & \\
CDS 2017-19 & $R=1-2 \omega^{G}$ & 0.14 & 0.14 \\
& $R=1-\omega^{G}$ & 0.26 & \\
Morikawa (2016,17) & $R=1-2 \omega^{G}-\omega^{K}$ & 0.07 & \\
Hoshi and Ito (2014) & & 0.02 & 0.15 \\
& & Very high & 0.23
\end{tabular}

Notes: $R$ represents the assumption of the recovery rate of government bonds during a crisis, which is used to calculate the crisis probability from the CDS spread data.

Table 3: Comparison of Untargeted Moments

\begin{tabular}{|c|c|c|c|c|c|}
\hline & Data & Benchmark model & & Data & Benchmark model \\
\hline $\mathrm{b} / \mathrm{y}$ & $0.5205(1.1501)$ & 0.838 & $\sigma(\mathrm{d} \log \mathrm{Y})$ & 0.021 & 0.021 \\
\hline$R^{G}-1$ & 0.019 & 0.039 & $\sigma(\mathrm{d} \log \mathrm{I})$ & 0.062 & 0.043 \\
\hline$R^{K}-R^{G}$ & 0.008 & 0.005 & $\sigma(\mathrm{d} \log \mathrm{C})$ & 0.016 & 0.017 \\
\hline$R^{D}-R^{G}$ & 0.001 & 0.003 & $\operatorname{cor}(\mathrm{d} \log \mathrm{Y}, \mathrm{b} / \mathrm{y})$ & -0.302 & -0.256 \\
\hline & & & $\operatorname{cor}(\mathrm{d} \log \mathrm{I}, \mathrm{b} / \mathrm{y})$ & 0.002 & -0.251 \\
\hline & & & $\operatorname{cor}\left(\operatorname{dlog} \mathrm{Y}, R^{G}-1\right)$ & 0.284 & 0.369 \\
\hline & & & $\operatorname{cor}\left(\mathrm{d} \log \mathrm{Y}, R^{K}-R^{G}\right)$ & -0.149 & -0.206 \\
\hline & & & $\operatorname{cor}\left(\operatorname{d} \log \mathrm{Y}, R^{D}-R^{G}\right)$ & 0.292 & -0.215 \\
\hline & & & $\operatorname{cor}\left(\mathrm{d} \log \mathrm{I}, R^{G}-1\right)$ & 0.058 & 0.174 \\
\hline & & & $\operatorname{cor}\left(\operatorname{d} \log \mathrm{I}, R^{K}-R^{G}\right)$ & -0.012 & -0.228 \\
\hline & & & $\operatorname{cor}\left(\operatorname{dlog} \mathrm{I}, R^{D}-R^{G}\right)$ & 0.023 & -0.237 \\
\hline
\end{tabular}

Notes: The data are from 1975 to 2019 for Japan. The model-based moments exclude the time of a crisis. Data $\mathrm{b} / \mathrm{y}$ represents the ratio of net government debt-to-output, whereas the figure in parentheses is the ratio of gross government debt-to-output. $\sigma(\mathrm{d} \log \mathrm{Y})$ is the only targeted moment.

Table 4: Welfare Comparison

\begin{tabular}{c|ccc} 
Model & $\mathrm{b} / \mathrm{y}$ & $\mathrm{y}$ & $\mathrm{U}$ \\
\hline Benchmark & 1.37 & 0.000 & 0.000 \\
All T tax & 0.99 & 0.192 & 0.066 \\
No K tax & 1.21 & 0.122 & 0.015 \\
No C tax & 1.37 & 0.003 & 0.000 \\
No G tax & 1.24 & 0.050 & 0.014 \\
High $\lambda^{Y}, \lambda^{D}$ & 1.16 & 0.100 & 0.046 \\
Always C tax & 0.70 & 0.109 & 0.053
\end{tabular}

Notes: The model includes the crisis periods. Output (y) and welfare ( $\mathrm{U}$, in the unit of consumption) are indicated as differences from the values in the benchmark model. 

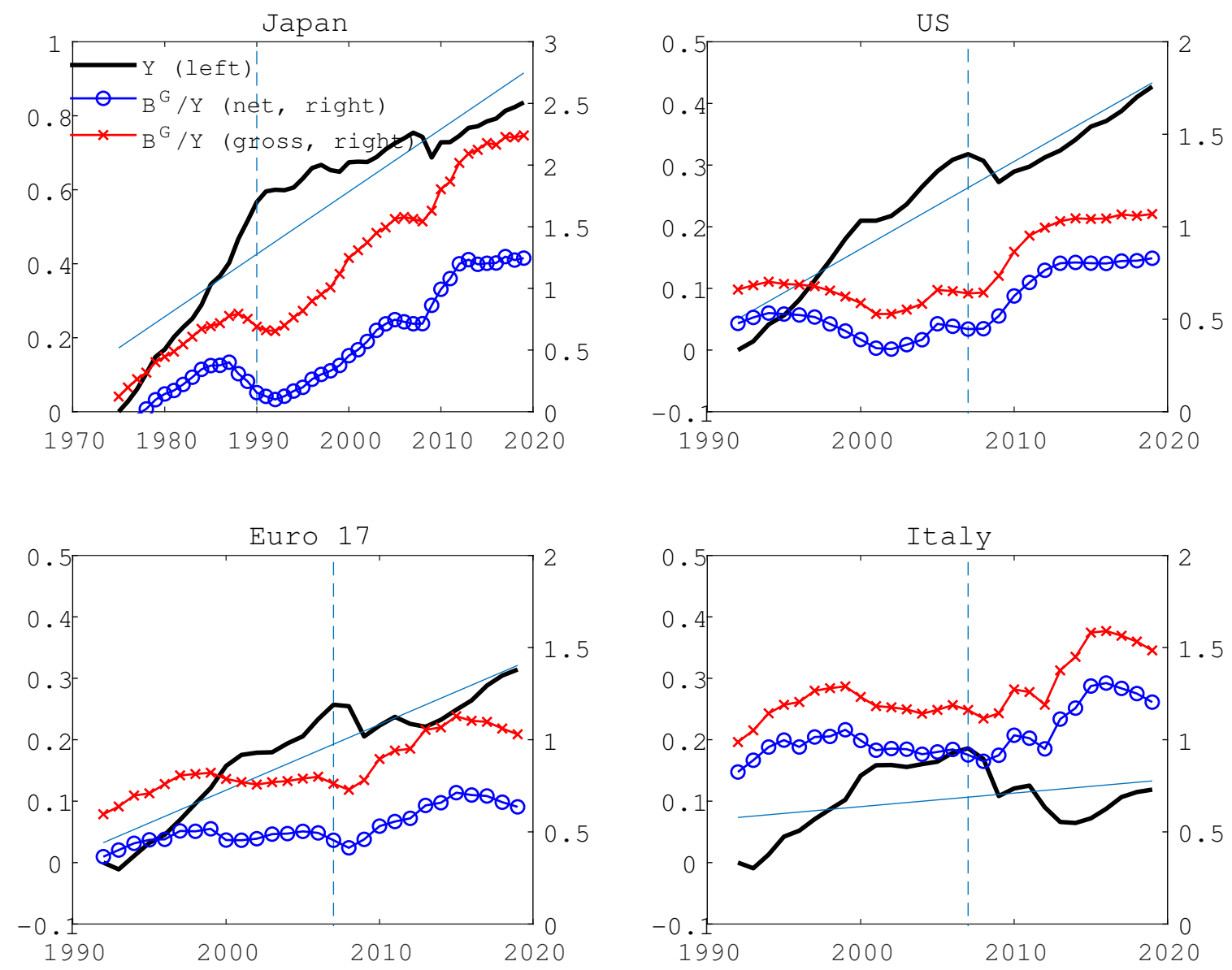

Figure 1: Government Debt and GDP

Note: The beginning year is 1975 for Japan and 1992 for the rest, representing a 15-year period before the financial crisis in each region (i.e., 1990 and 2007, respectively, shown as the vertical dashed line). The thick solid line represents the logarithm of real GDP per capita (set to zero in the first year), shown on the left axis. The thin solid line represents its linear trend. On the right axis, the line with crosses and the line with circles represent the ratio of gross and net government debt, respectively, to nominal GDP. 


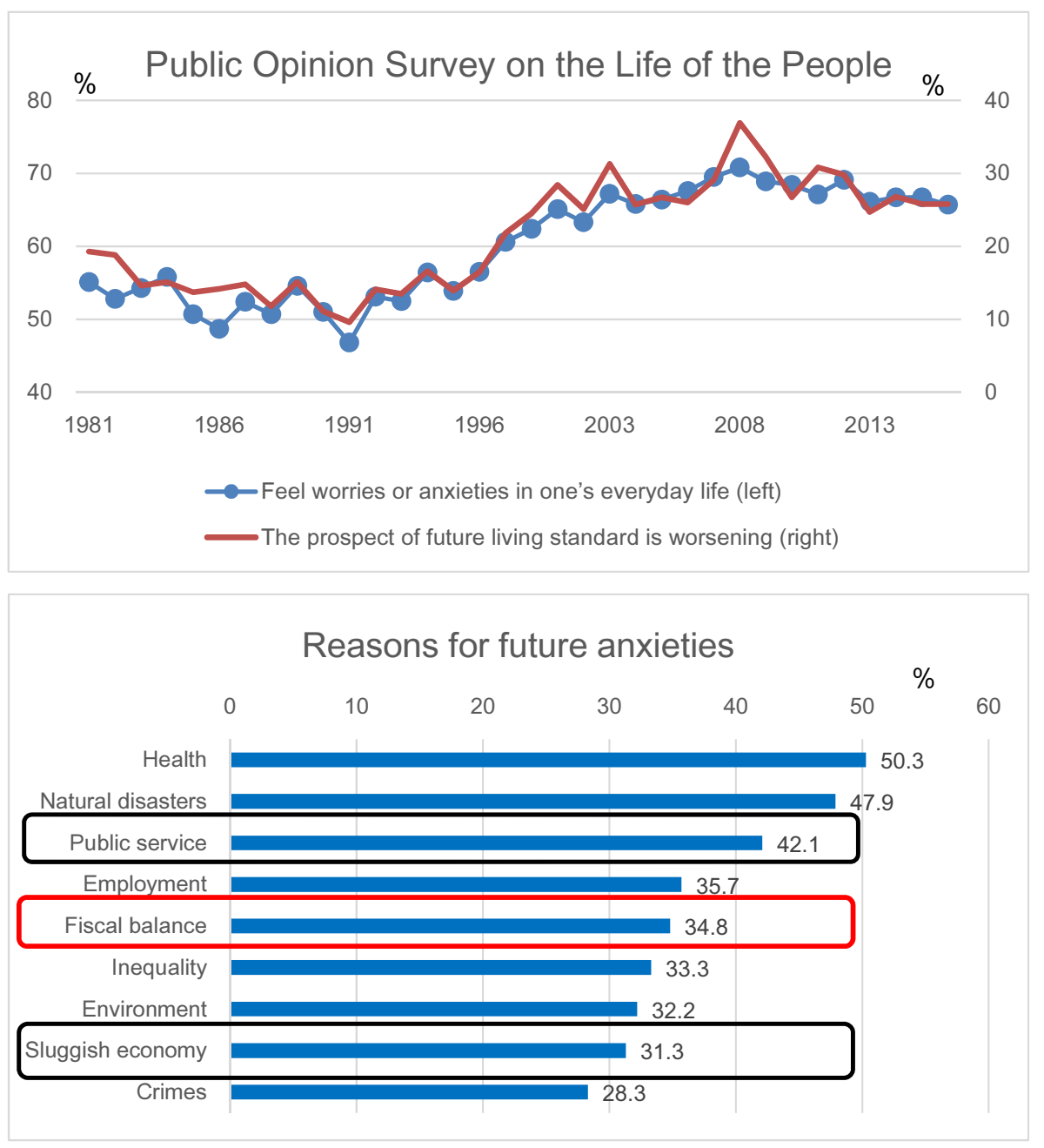

Figure 2: Japanese Sentiment

Source: Cabinet Office "Overview of the Public Opinion Survey on the Life of the People"
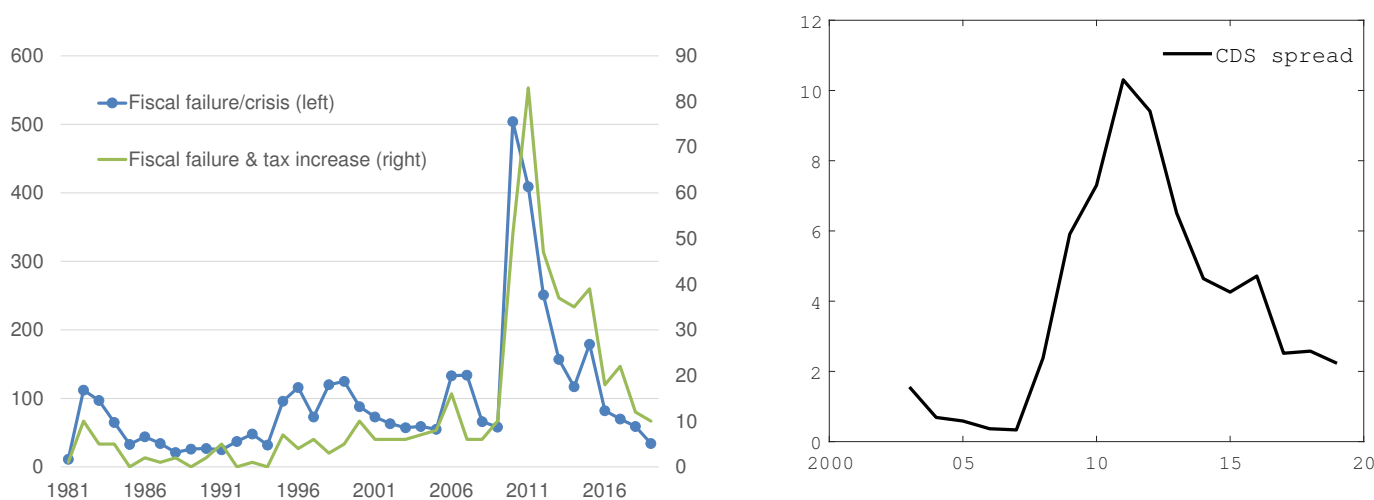

Figure 3: Concerns about the Government Debt Crisis

Note: The left-hand figure shows the number of occurrences of specific words in the morning and evening editions of the Nihon Keizai Shinbun, Japan's financial newspaper, for each year. The right-hand figure shows the sovereign CDS spread with a five-year maturity. The data are taken from Bloomberg. 

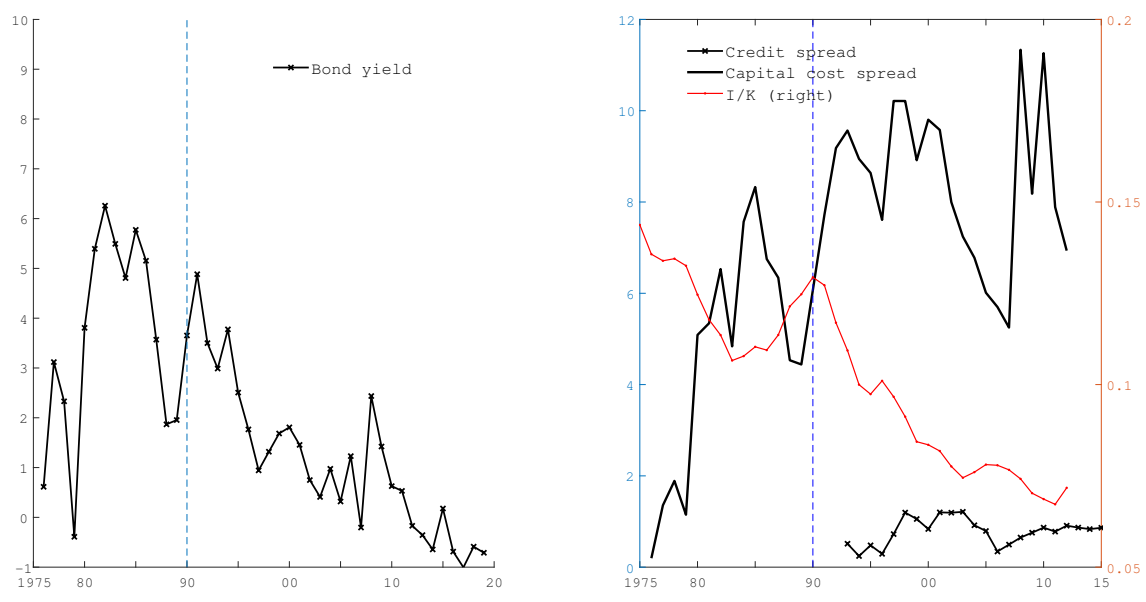

Figure 4: Bond Yield, Credit Spread, and Investment

Note: The government bond yield, in real terms, is defined as that with a five-year maturity minus the annual CPI inflation rate in the following year. The credit spread is defined as the bank loan rate with one-year maturity or longer minus the government bond yield with five-year maturity. The data on investment, capital, and capital cost are obtained from the JIP database (https://www.rieti.go.jp/en/database/jip.html). The capital cost spread is defined as the rental cost minus the five-year government bond yield.

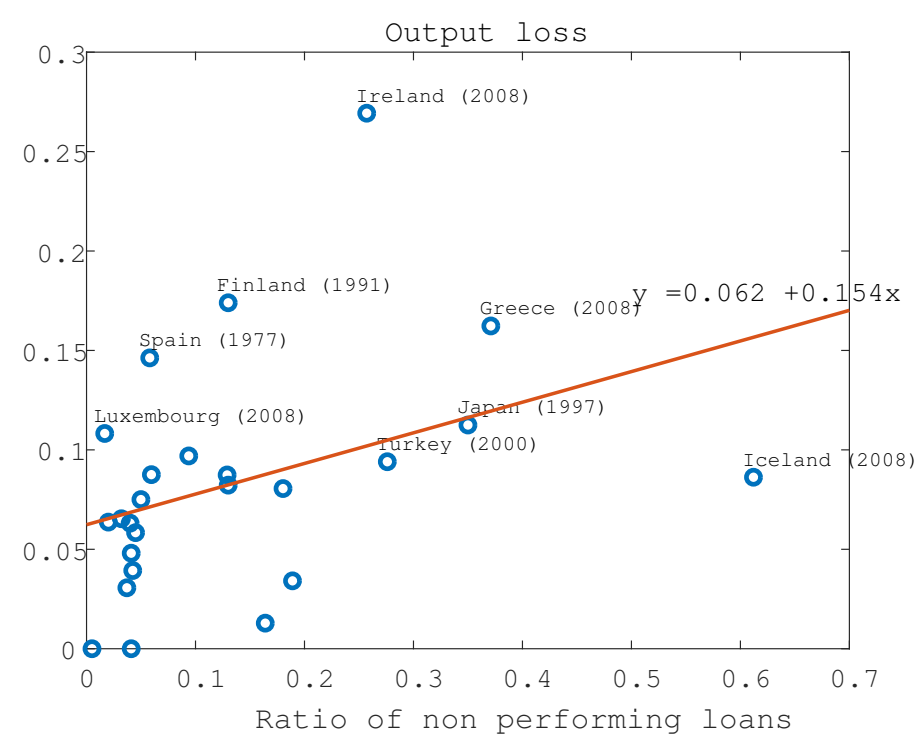

Figure 5: Relation Between Output Loss and Banks' Nonperforming Loans The source is Laeven and Valencia (2018). 

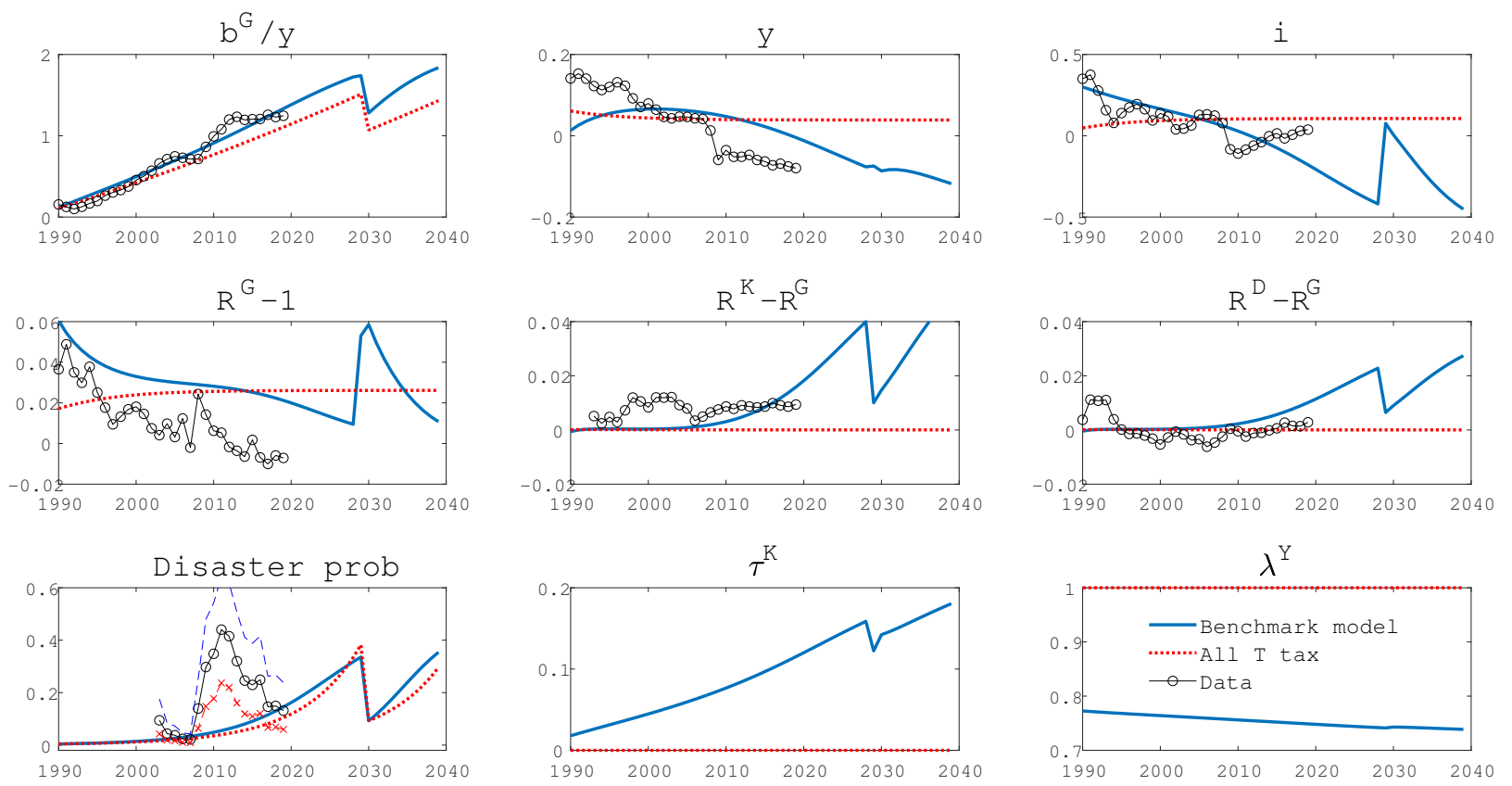

Figure 6: Simulation Results of the Benchmark Model
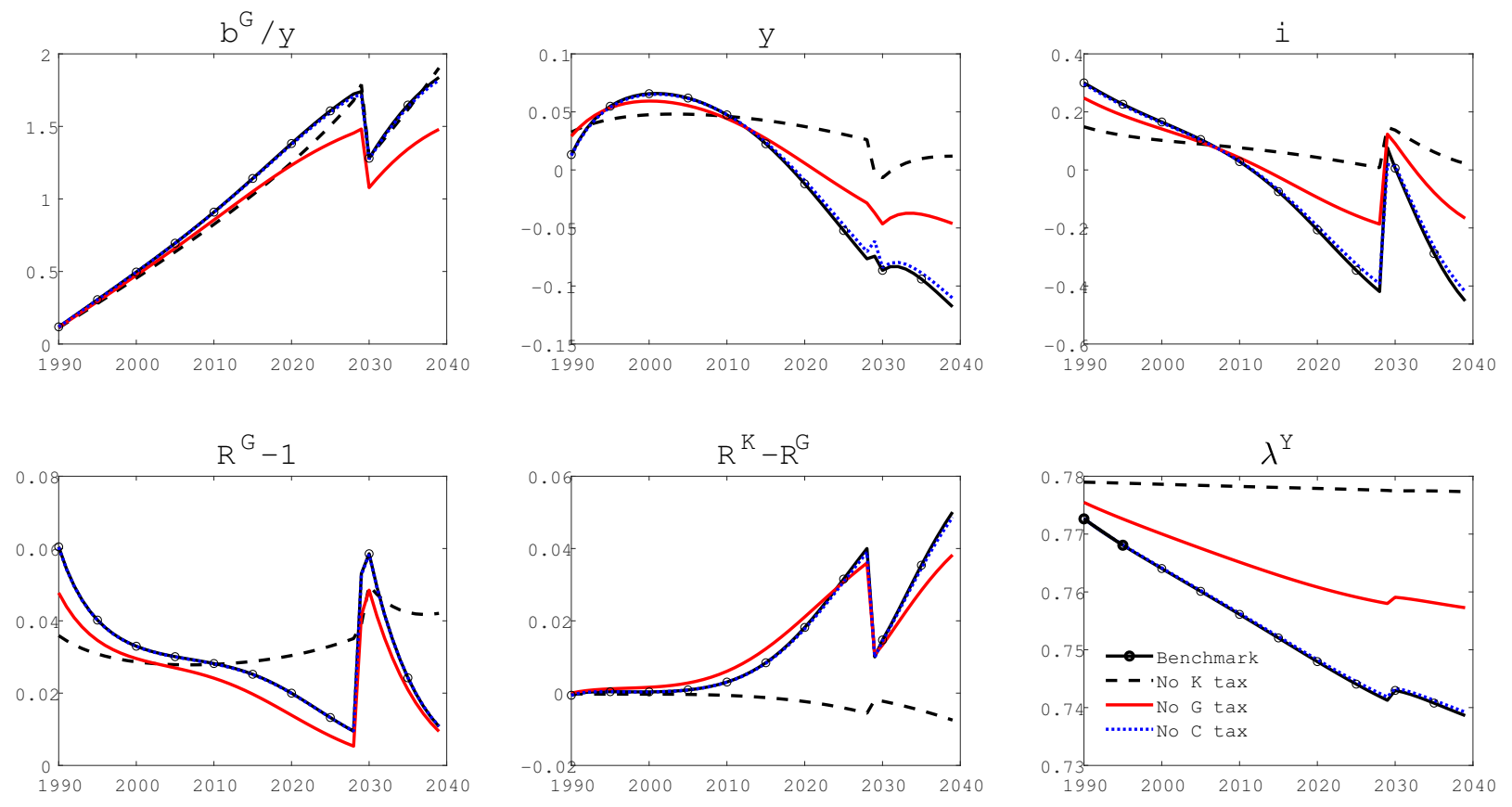

Figure 7: Simulation Results in Different Tax Scenarios at Crisis 

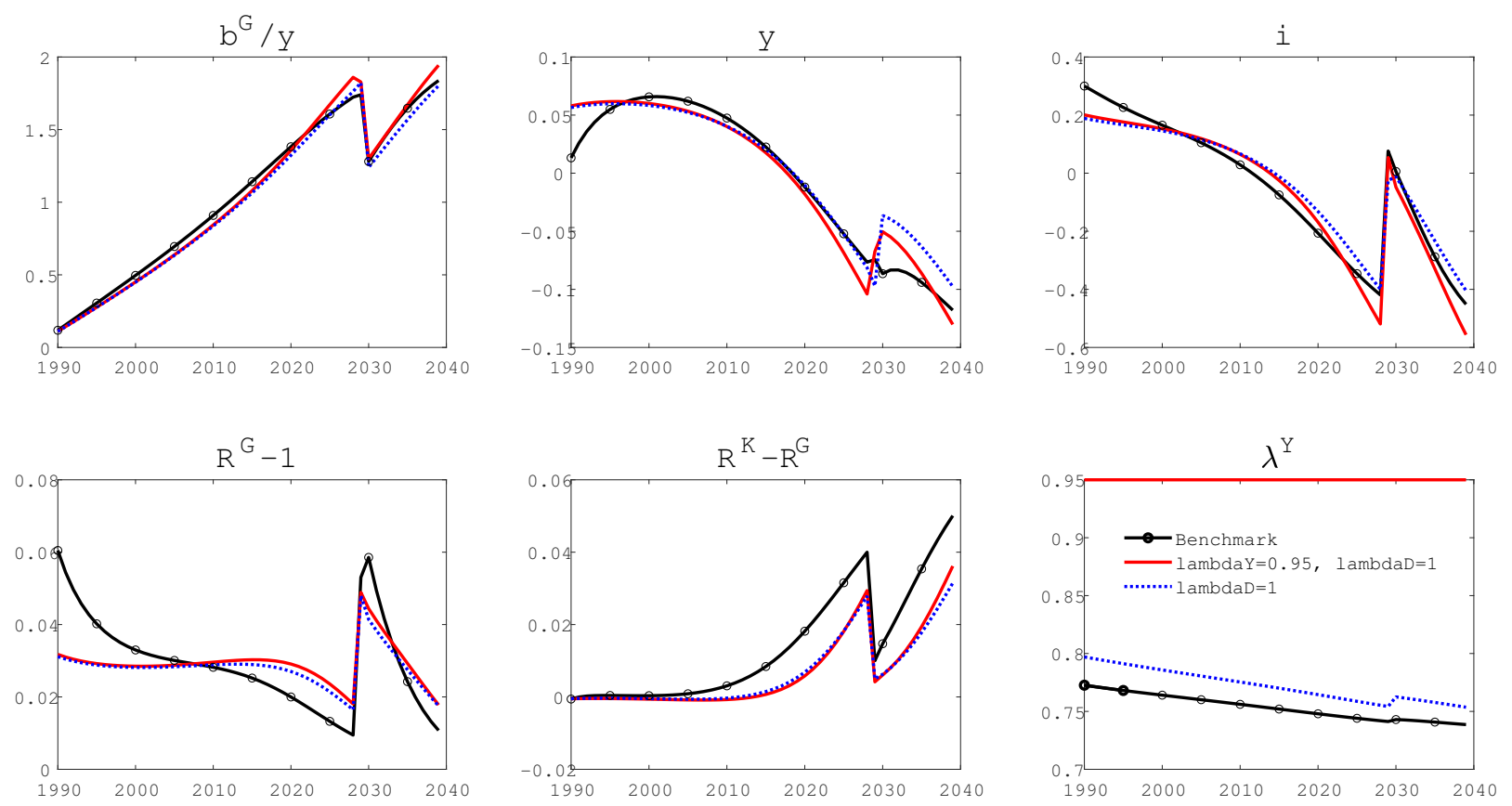

Figure 8: Simulation Results when Capita-Use Inefficiency is Small
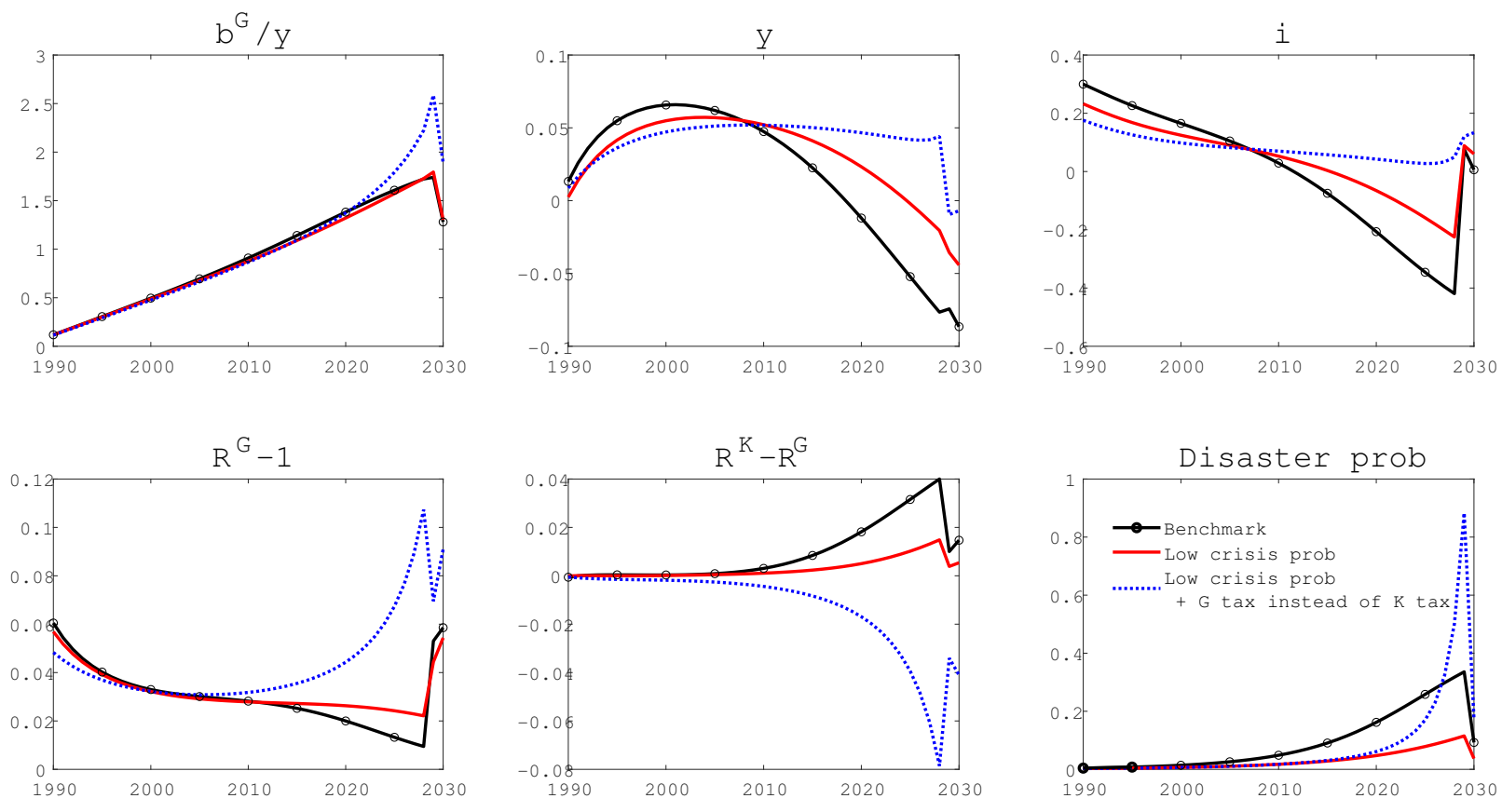

Figure 9: Simulation Results when the Crisis Probability is Low 